\title{
Vesicular Glutamate Transporter 2 Is Required for Central Respiratory Rhythm Generation But Not for Locomotor Central Pattern Generation
}

\author{
Åsa Wallén-Mackenzie, ${ }^{1}$ Henrik Gezelius, ${ }^{1 \star}$ Muriel Thoby-Brisson, ${ }^{2 \star}$ Anna Nygård, ${ }^{1}$ Anders Enjin, ${ }^{1}$ Fumino Fujiyama, ${ }^{3}$ \\ Gilles Fortin, ${ }^{2}$ and Klas Kullander ${ }^{1}$ \\ ${ }^{1}$ Department of Neuroscience, Unit of Developmental Genetics, Uppsala University, 75123 Uppsala, Sweden, ${ }^{2}$ Laboratoire de Neurobiologie Génétique et \\ Intégrative, Institut Alfred Fessard, Centre National de la Recherche Scientifique, 91198 Gif sur Yvette, France, and ${ }^{3}$ Department of Morphological Brain \\ Science, Graduate School of Medicine, Kyoto University, Kyoto 606-8501, Japan
}

\begin{abstract}
Glutamatergic excitatory neurotransmission is dependent on glutamate release from presynaptic vesicles loaded by three members of the solute carrier family, Slc17a6 - 8, which function as vesicular glutamate transporters (VGLUTs). Here, we show that VGLUT2 (Slc17a6) is required for life ex utero. Vglut 2 null mutant mice die immediately after birth because of the absence of respiratory behavior. Investigations at embryonic stages revealed that neural circuits in the location of the pre-Bötzinger (PBC) inspiratory rhythm generator failed to become active. However, neurons with bursting pacemaker properties and anatomical integrity of the PBC area were preserved. Vesicles at asymmetric synapses were fewer and malformed in the Vglut2 null mutant hindbrain, probably causing the complete disruption of AMPA/kainate receptor-mediated synaptic activity in mutant $\mathrm{PBC}$ cells. The functional deficit results from an inability of PBC neurons to achieve synchronous activation. In contrast to respiratory rhythm generation, the locomotor central pattern generator of Vglut2 null mutant mice displayed normal rhythmic and coordinated activity, suggesting differences in their operating principles. Hence, the present study identifies VGLUT2-mediated signaling as an obligatory component of the developing respiratory rhythm generator.
\end{abstract}

Key words: central pattern generator; rhythm; glutamate; respiration; network; physiology; development; transmitter

\section{Introduction}

Central pattern generators (CPGs) are defined as neuronal circuits capable of producing a rhythmic and coordinated output without the influence of sensory input. The respiratory and locomotor neuronal circuits are two of the better characterized CPGs, although much work remains to fully understand how these networks operate. Glutamatergic neurons are involved in most neuronal circuits of the nervous system and considerable efforts have been made to study the role of glutamate receptors in nervous system signaling using a variety of approaches. It has been difficult to pinpoint the role of glutamatergic neurons in neuronal

Received Sept. 5, 2006; revised 0ct. 10, 2006; accepted 0ct. 11, 2006.

This work was supported by grants from the Swedish Research Council (K2004-32P-15230-01A, K2005-33X15327-01A), the foundations of Knut and Alice Wallenberg, Åke Wiberg, and Magnus Bergvall, Uppsala University (K.K.), Swedish Brain Foundation (Å.W.-M.), Centre National de la Recherche Scientifique, and Réunions InterOrganismes Imagerie Gif, which is supported by Action de Soutien à la Technologie et la Recherche en Essonne. We thank the Uppsala University Transgenic Facility and Biomedical Center-Electron Microscopy Department of Medical Cell Biology, Gothenburg University Core Facility, Å. Fex-Svenningsen, N. Rabe, K. Krumkühler, and A.-K. Johnson for excellent work, and Dr. C. Goridis for the generous gift of Phox2b plasmid and antibody. We also thank Dr. 0. Kiehn for valuable help with locomotor electrophysiology, L. Wrobel for help with plethysmographic recordings, and Drs. H. Bengtsson, A. Vallstedt, I. Ferby, and T. Mäkinen for critical reading of this manuscript.

*H.G. and M.T.-B. contributed equally to this work

Correspondence should be addressed to either of the following: Klas Kullander, Department of Neuroscience, Unit of Developmental Genetics, Uppsala University, P.0. Box 587, 75123 Uppsala, Sweden, E-mail: klas.kullander@ neuro.uu.se; or Gilles Fortin, Laboratoire de Neurobiologie Génétique et Intégrative, Institut Alfred Fessard, Centre National de la Recherche Scientifique, 91198 Gif sur Yvette, France, E-mail: gilles.fortin@iaf.cnrs-gif.fr.

DOI:10.1523/JNEUROSCI.3855-06.2006

Copyright $\odot 2006$ Society for Neuroscience $\quad$ 0270-6474/06/2612294-14\$15.00/0 circuits because of the complexity of glutamate-mediated signaling and the variety of receptors triggered by glutamate. In addition, glutamate is an amino acid used by every cell, which has hampered identification of glutamatergic neurons. The discovery of the vesicular glutamate transporter (VGLUT) proteins, which transport glutamate into presynaptic vesicles (Bellocchio et al., 2000; Takamori et al., 2000, 2001; Fremeau et al., 2001; Herzog et al., 2001), has enabled a novel approach to identify and interfere with presynaptic release of glutamate. Recently, mice with a targeted deletion of the Vglut1 gene were unexpectedly demonstrated to be viable, although they displayed progressive neurodegeneration and died prematurely (Fremeau et al., 2004; Schuske and Jorgensen, 2004; Wojcik et al., 2004).

The pre-Bötzinger complex (PBC) is an inspiratory oscillator network within the respiratory CPG primarily pacing the respiratory rhythm (Smith et al., 1991; Koshiya and Smith, 1999; Feldman and Del Negro, 2006). It is located in the rostroventrolateral medulla and relies on excitatory glutamatergic connections (Funk et al., 1993; Rekling and Feldman, 1998). PBC interneurons discharge through activation of NMDA and non-NMDA glutamate receptors (Funk et al., 1993, 1997) and are immunopositive for glutamate receptor subunits (Robinson and Ellenberger, 1997; Paarmann et al., 2005). Neurokinin-1-receptor (NK1R)-expressing PBC neurons, essential for maintenance of normal breathing in vivo (Gray et al., 2001; McKay et al., 2005), have been shown to contain Vglut2 mRNA and to receive 
VGLUT2-positive terminals (Gray et al., 1999; Guyenet et al., 2002; Stornetta et al., 2003a,b) but also have GABAergic and glycinergic terminals (Liu et al., 2002). The locomotor CPG is located in the ventral part of the lumbar spinal cord (Kjaerulff and Kiehn, 1996) and controls rhythmically alternating activity between the left and right sides and flexor-extensor muscles. In vivo, locomotor activity is likely initiated by glutamatergic descending pathways from the brain (Mori et al., 2001). In the in vitro spinal cord preparation, fictive locomotion can be induced by bath application of neurotransmitters or their agonists, like dopamine, 5-HT, and NMDA (Jiang et al., 1999; Cazalets et al., 2000; Nishimaru et al., 2000). Data mainly derived from studies in lamprey and mouse have suggested that the locomotor CPG in both developing and adult vertebrates is built on inhibitory components and excitatory glutamatergic components (Buchanan and Grillner, 1987; Grillner, 1997, 2003; Kiehn, 2006).

Here, we have genetically eliminated presynaptic release of glutamate mediated by VGLUT2 in the mouse and present evidence that VGLUT2 is necessary for life ex utero. We further demonstrate that respiratory-related rhythm generation in the $\mathrm{PBC}$ fails to initiate during embryonic development leading to absence of respiration. Targeted deletion of Vglut 2 has no notable consequence on the anatomy of the brainstem but affects the number and morphology of excitatory synaptic vesicles in the brainstem. As a probable consequence, we have observed a complete loss of AMPA/kainate-mediated excitatory synaptic processing in neurons of the PBC area of Vglut $2^{f / f P C r e}$ mutants. This results in an absence of population synchronized activity. In contrast, activity of the spinal locomotor CPG is spared by the mutation, suggesting that VGLUT2 is specifically required in the respiratory CPG. This $\mathrm{Vglut} 2^{f / ; P C r e}$ mutant mouse represents the first genetic model showing complete uncompensated functional impairment of the respiratory CPG.

\section{Materials and Methods}

Generation of Vglut2 null animals. The Vglut2 targeting construct was built by conventional and Red-ET recombination cloning (Zhang et al., 2000). In the construct, exons 4,5 , and 6 were flanked by an upstream loxP site and downstream by an FRT-flanked neo cassette followed by a second loxP site. A dual prokaryotic/eukaryotic promoter enabling kanamycin resistance selection in bacteria and neomycin resistance in embryonic stem (ES) cells preceded the neo cassette. ES cells (Sv129/R1) were electroporated with the targeting construct and the modified allele was detected by standard PCR using oligos that recognized the $5^{\prime}$-loxP site, the neo cassette, and the $3^{\prime}$-loxP site. Positive clones were also confirmed by Southern blot analysis of the $3^{\prime}$ end using a probe directed against the neo cassette after digestion with BstEII. Two ES clones were selected for blastocyst (C57BL/6) injection, which produced a large number of chimeric mice. These were bred with C57BL/6 mice to generate heterozygous mice carrying one floxed allele $\left(V_{g l u t} 2^{f /+}\right)$, which were then intercrossed to produce homozygous mice $\left(\right.$ Vglut $\left.^{f / f}\right)$. Vglut $2^{f / f}$ mice were crossed to PGK-Cre mice (Lallemand et al., 1998) to generate null mutant mice ( $\mathrm{Vglut} 2^{f / ; P C r e}$ ). The neo cassette was removed by crossing Vglut $2^{f /+}$ mice to Deleter-FlpE mice (Rodriguez et al., 2000). As controls, littermates with at least one wild-type (wt) allele were used. All experiments involving live animals were performed in accordance with ethical guidelines defined by the French Agricultural Ministry and the European Union Council Directive for the Care and Use of Laboratory Animals (number 2889) and have been approved by the appropriate local Swedish ethical committee (C156/4).

Genotyping by PCR. For genotyping of mice, $1-2 \mathrm{~mm}$ of tail was incubated in $75 \mu \mathrm{l}$ of buffer consisting of $25 \mathrm{~mm} \mathrm{NaOH}$ and $200 \mu \mathrm{M}$ EDTA at $96^{\circ} \mathrm{C}$ for $45 \mathrm{~min}$ and placed on ice for a few minutes. Tris- $\mathrm{HCl}(40 \mathrm{~mm})$, $\mathrm{pH} 8.0$, was then added to a final volume of $150 \mu \mathrm{l}$, after which the preparations were subjected to PCR analysis. Oligos a and b (see Fig. $1 \mathrm{~A}$ ) detects a $150 \mathrm{bp}$ fragment in the wt allele and a $184 \mathrm{bp}$ band in the floxed allele. Oligos a and c (see Fig. $1 \mathrm{~A}$ ) detects a $327 \mathrm{bp}$ fragment in the null allele and no band in the wt and floxed allele, respectively. A separate Cre-specific PCR was run to verify the presence of the PGK-Cre allele. In addition, Neo and Deleter-FlpE specific PCRs were used to genotype Neo-excised mice.

Preparation of tissue and histology. Animals were mated overnight, and females were checked for vaginal plug the next morning. In the morning of plug, embryos were staged as embryonic day 0.5 (E0.5). Embryos were collected at E12.5, E15.5, E16.5, and E18.5. In the morning of E19, pups were born. Newborn pups are denoted as postnatal day 0 (P0). For dissection of embryos, pregnant females were killed by cervical dislocation and embryos were removed. E12.5 embryos were kept intact, whereas older embryos and newborn pups were decapitated and the skin was removed. Tails were collected for genotyping. The animals were fixed in zinc-formalin (Richard-Allan Scientific, Kalamazoo, MI) for 18-24 h at room temperature before dehydration and paraffin infusion (Tissue Tek vacuum infiltration processor; Miles Scientific, Elkhart, IN). Sections (7 $\mu \mathrm{m}$ thick) were cut on Microm microtome, attached on Superfrost slides (Menzel-Gläser, Braunschweig, Germany) and stored at $4^{\circ} \mathrm{C}$ until usage. Slides were deparaffinized in X-tra solve (Medite Histotechnic, Burgdorf, Germany) and rehydrated in ethanol/water before subsequent treatments. For hematoxylin (Richard-Allan Scientific) and eosin (Sigma, St. Louis, MO) histological staining, slides were incubated in hematoxylin $20-30 \mathrm{~s}$, rinsed in water, $0.1 \%$ ammonium hydroxide, and water again before incubation in eosin 20-30s followed by water. Slides were then dehydrated in ethanol/water, infused in X-tra solve, and mounted.

In situ hybridization histochemistry. For paraffin in situ hybridization histochemistry, rehydrated paraffin sections were fixed for $10 \mathrm{~min}$ in $4 \%$ formaldehyde, washed in PBS, and treated with proteinase K (Sigma; 27 $\mu \mathrm{g} / \mathrm{ml}$ diluted in $10 \mathrm{~mm}$ Tris- $\mathrm{HCl} / 1 \mathrm{~mm}$ EDTA, $\mathrm{pH}$ 8.0) for $5 \mathrm{~min}$. After refixation and washes in $\mathrm{PBS}$, the slides were acetylated for $10 \mathrm{~min}$ in a mixture of $1.3 \%$ triethanolamine (Sigma), $0.2 \%$ acetic anhydride (Fluka, Neu-Ulm, Germany), and $0.06 \% \mathrm{HCl}$ diluted in water. Slides were then incubated for $30 \mathrm{~min}$ in PBS containing 1\% Triton X-100 (Sigma). After subsequent washes in PBS, slides were prehybridized for $2-5 \mathrm{~h}$ in hybridization solution without probe [ $50 \%$ formamide (Fluka), $5 \times$ SSC, $5 \times$ Denhardt's, $250 \mu \mathrm{g} / \mathrm{ml}$ yeast transfer RNA (Sigma), $500 \mu \mathrm{g} / \mathrm{ml}$ sheared salmon sperm DNA (Ambion, Austin, TX) diluted in water]. Probes were diluted to $0.1-1 \mu \mathrm{g} / \mathrm{ml}$ in hybridization solution and heated to $80^{\circ} \mathrm{C}$. Sections were then hybridized with $100 \mu$ l of hybridization solution for $16 \mathrm{~h}$ at $70^{\circ} \mathrm{C}$. The next day, slides were dipped in prewarmed $5 \times$ SSC, transferred to $0.2 \times \mathrm{SSC}$, and incubated for $2 \mathrm{~h}$ at $70^{\circ} \mathrm{C}$. After one wash in $0.2 \times$ SSC at room temperature and one wash in B1 solution $(0.1 \mathrm{M}$ Tris- $\mathrm{HCl}, \mathrm{pH} 7.5$, and $0.15 \mathrm{M} \mathrm{NaCl}$ ), sections were immunoblocked with $10 \%$ fetal calf serum in $\mathrm{B} 1$, and then incubated overnight at $+4^{\circ} \mathrm{C}$ with alkaline phosphatase-conjugated anti-digoxigenin Fab fragments (Roche, Mannheim, Germany) diluted 1:5000 in B1 containing 1\% fetal calf serum. The following day, slides were washed in B1, equilibrated in B3 (0.1 м Tris- $\mathrm{HCl}, \mathrm{pH} 9.5,0.1 \mathrm{M} \mathrm{NaCl}, 50 \mathrm{~mm} \mathrm{MgCl}$ ), and color developed in a $10 \%$ polyvinyl alcohol (Sigma) solution also containing 100 mм Tris- $\mathrm{HCl}, \mathrm{pH} 9.5,100 \mathrm{~mm} \mathrm{NaCl}, 5 \mathrm{~mm} \mathrm{MgCl}_{2}, 0.17 \%$ nitroblue tetrazolium (Roche), 0.17\% 5-bromo-4-chloro-3-indolyl phosphate (Roche), and $1 \mathrm{~mm}$ levamisole (Sigma). Staining was sufficient after 6-24 $\mathrm{h}$, whereupon slides were washed in water and mounted.

Probes. The Vglut2 probe covers nucleotides 1616-2203, vesicular acetylcholine transporter (VAChT) 1534-2413, tyrosine hydroxylase (TH) 1300-1754. The VGlut1 and Phox2b probes have been described previously (Kullander et al., 2003; Pattyn et al., 2000b).

Immunofluorescence. For immunofluorescence histochemistry, rehydrated paraffin sections were boiled for $10 \mathrm{~min}$ in $0.1 \mathrm{M}$ citric acid (VWR International, Leicestershire, UK), $\mathrm{pH}$ 6.0, left to cool for 20-30 min, washed in PBS, and incubated with primary antibodies (guinea pig VGLUT2) diluted to $1 \mu \mathrm{g} / \mathrm{ml}$ [described by Fujiyama et al. (2001) and Hioki et al. (2003) ]; mouse TH (Chemicon, Temecula, CA), 1:200; rabbit NK1R (Sigma), 1:5000; guinea pig islet1,2 (gift from J. Ericson, Karolinska Institute, Stockholm, Sweden), 1/1000; and Phox2b, 1:500 (Pattyn et al., 2000b) in PBS with $0.3 \%$ Triton X-100 at room temperature overnight. The following day, slides were washed in PBS and incubated with 
Alexa fluorescent secondary antibodies (Invitrogen, San Diego, CA) diluted $1: 200$ in PBS with $0.3 \%$ Triton X-100 and $10 \%$ goat serum for $>2 \mathrm{~h}$ at room temperature. Slides were then washed in PBS, incubated with 1 $\mu \mathrm{g} / \mathrm{ml} \mathrm{4}$ 4 $^{\prime} 6^{\prime}$-diamidino-2-phenylindole (DAPI) (Sigma), washed again, and mounted.

Imaging. Fluorescent and bright-field stainings were analyzed using an Olympus (Tokyo, Japan) microscope with an Optigrid system (Thales, Fairport, NY) and Volocity software (Improvision, Lexington, MA); fluorescent stainings were also analyzed by confocal microscopy using Zeiss (Oberkochen, Germany) LSM 510 META system and bright-field stainings on a MZ16F dissection microscope with DFC300FX camera and FireCam software (Leica, Nussloch, Germany). Captured images were auto-leveled using Adobe Photoshop software.

Electron microscopy. For electron microscopy (EM), E18.5 embryos were dissected and brains were rapidly placed in $2.5 \%$ glutaraldehyde (Sigma). After $1 \mathrm{~h}$ of fixation, brains were cut in 1-mm-thick coronal sections using a brain matrix, and from these slices, round pieces of $1 \mathrm{~mm}$ in diameter were punched out from the following regions: olfactory bulb, cortex/hippocampus border, thalamus, striatum, medulla, and pons. The punches (from two control brains and two null mutant brains) were mounted in Epon plastic, sectioned at $1 \mu \mathrm{m}$, and stained in toluidine blue, after which the punches were appropriately cut in one-third to allow ultrathin sectioning into $50 \mathrm{~nm}$ slices (three slices per region) for EM analysis. The slices were contrast stained with 5\% uranyl acetate and lead citrate for analysis on a Hitachi H-700 EM (Hitachi Scientific Instruments, Nissei Sangyo, Tokyo, Japan). Synaptic structures were analyzed morphologically in all brain areas. Synapses with both presynaptic and postsynaptic membrane thickening were defined as symmetric, whereas those with only a postsynaptic thickening were defined as asymmetric. In the control brains, symmetric vesicles were either round or displayed a flattened appearance, whereas asymmetric vesicles were always round. In the null mutant, symmetric vesicles looked as in the control, whereas the asymmetric vesicles frequently displayed an irregular shape (see Results). The medulla was selected for synaptic vesicle quantification. Three consecutive medullary slices were analyzed per animal, and values given are averages per genotype \pm SEM. The number of vesicles per synapse was subdivided into groups of $1,2-8,9-18,19-25$, and $>25$ vesicles per synapse. Photographs were taken at 40,000× magnification.

In vivo measurement of the ventilation. Pregnant mice were killed by cervical dislocation at E18.5, and fetuses surgically delivered from uterine horns were transferred into a ventilation recording chamber. Ventilation was monitored using a barometric method (Bartlett and Tenney, 1970). The plethysmograph chamber $(15 \mathrm{ml})$ equipped with a temperature sensor, was connected through a slow leak to a reference chamber of the same volume. The pressure difference between the two chambers was measured with a differential pressure transducer (DP-103-10; Validyne, Northridge, CA) connected to sine wave demodulator (CD15; Validyne). The spirogram was stored on a personal computer (PC) (Chatonnet et al., 2002). Calibrations were made during each recording session by injecting $5 \mu \mathrm{l}$ of air into the experimental chamber with a Hamilton syringe. Mean values for the ventilatory frequency were calculated from averaging 100 breaths.

Brainstem electrophysiology. Pregnant mice were killed by cervical dislocation on E16.5 to E18.5. Isolated whole hindbrain preparations and transverse slices containing the $\mathrm{PBC}$ were prepared according to previously published protocols (Thoby-Brisson et al., 2005). Embryos were excised from the uterus and kept in oxygenated artificial CSF (aCSF) at room temperature until the electrophysiological recording session. aCSF composition was as follows (in $\mathrm{mM}$ ): $128 \mathrm{NaCl}, 8 \mathrm{KCl}, 1.5 \mathrm{CaCl}_{2}, 1$ $\mathrm{MgSO}_{4}, 24 \mathrm{NaHCO}_{3}, 0.5 \mathrm{Na}_{2} \mathrm{HPO}_{4}, 30$ glucose, $\mathrm{pH}$ 7.4. One transverse $450-\mu \mathrm{m}$-thick slice was prepared from each embryo using a vibratome, and then transferred to a recording chamber continuously superfused with oxygenated aCSF, at $30^{\circ} \mathrm{C}$. Hypoglossal nerve root activity in whole hindbrain preparations and local population activity in slices were recorded using glass micropipettes suction electrodes (150 $\mu \mathrm{m}$ tip diameter). The micropipettes filled with aCSF were connected through silver wires to a high-gain AC amplifier (7P511; Grass, West Warwick, RI), filtered (bandwidth, $3 \mathrm{~Hz}$ to $3 \mathrm{kHz}$ ), integrated using an electronic filter (Neurolog System; time constant, $100 \mathrm{~ms}$ ), recorded on a computer via a digitizing interface (Digidata 1322A; Molecular Devices, Foster City, $\mathrm{CA}$ ), and analyzed with the pClamp9 software (Molecular Devices). Whole-cell patch-clamp neuronal recordings were performed under visual control using differential interference contrast and infrared video microscopy, an Axoclamp2A amplifier (Molecular Devices), a digitizing interface (Digidata 1322A; Molecular Devices), and the software program pClamp9 (Molecular Devices). Patch electrodes (resistance, 4-6 $\mathrm{M} \Omega$ ) were pulled from borosilicate glass tubes (GC 150TF; Clark, Pangbourn, UK) and filled with a high chloride internal solution containing the following (in mM): $123 \mathrm{~K}$-gluconic acid, $21 \mathrm{KCl}$, $0.5 \mathrm{EGTA}, 3 \mathrm{MgCl}_{2}$, 10 HEPES, pH 7.2. Ongoing synaptic currents were recorded at a holding potential of $-70 \mathrm{mV}$. The inward direction of synaptic currents mediated by $\mathrm{GABA}_{\mathrm{A}}$ and glycine receptors was imposed by our recording conditions to mimic the immature transmembrane chloride gradient enforcing, at the embryonic time of recording, a depolarizing action of GABA (Thoby-Brisson et al., 2005). Drugs were obtained from Sigma, dissolved in aCSF, and bath applied for 10-15 min at the following final concentrations (in $\mu \mathrm{M}$ ): 0.1 for substance P (SP), 0.3 for D-Ala2, MePhe4,Gly-ol5-enkephalin (DAMGO), 10 for 6-cyano-7nitroquinoxaline-2,3-dione (CNQX), 10 for bicuculline, 5 for strychnine, and 1000 for NMDA. A pressure pulse ( $50 \mathrm{~ms} ; 0.5$ bar) was applied to a patch pipette filled with AMPA ( $1 \mathrm{mM}$ ) diluted in aCSF, positioned right below the surface of the slice over the $\mathrm{PBC}$ area to test the presence of orthodromically evoked excitatory responses in the contralateral PBC area. A concentric bipolar stimulation electrode (Phymep, Paris, France) was positioned at the surface of the slice on the $\mathrm{PBC}$ area and at a ventral level on the midline to stimulate commissural fibers connecting the PBCs bilaterally. Values are given as means \pm SEM.

Calcium imaging. Whole hindbrain and slices were incubated for 45 min in oxygenated aCSF containing the cell-permeable calcium indicator dye Calcium Green-1AM (10 $\mu$; Invitrogen). Whole hindbrain preparations were positioned in the recording chamber with the ventral side up to allow optical accessibility of the facial motor nuclei. After a $30 \mathrm{~min}$ recovery period in the recording chamber to wash out the dye, a standard epifluorescent illumination system on an E-600-FN upright microscope (Nikon, Tokyo, Japan) equipped with a fluorescein filter block was used to excite the dye and capture the emitted light. Fluorescence images were captured with a cooled CCD camera (Coolsnap HQ; Photometrics, Tucson, AZ) using an exposure time of $100 \mathrm{~ms}$ in overlapping mode (simultaneous exposure and readout) during periods of 30-120 s and analyzed using MetaMorph software (Universal Imaging, West Chester, PA). The average intensity in a region of interest was calculated for each frame, and changes in fluorescence were normalized to their initial value by expression as the ratio of changes in fluorescence to initial fluorescence $(\Delta F / F)$.

Spinal cord electrophysiology. The functional output of the locomotor CPG was studied using extracellular electrophysiology on an in vitro preparation of the spinal cord (for review, see Whelan, 2003). The embryos were decapitated just before dissection and mounted ventral side up in a dissection chamber. After filling the chamber with ice-cold oxygenated $\left(95 \% \mathrm{O}_{2}\right.$ plus $5 \% \mathrm{CO}_{2}$ ) dissection buffer (in mM: $128 \mathrm{NaCl}, 4.69$ $\mathrm{KCl}, 25 \mathrm{NaHCO}_{3}, 1.18 \mathrm{KH}_{2} \mathrm{PO}_{4}, 3.5 \mathrm{MgSO}_{4}, 0.25 \mathrm{CaCl}_{2}, 22$ D-glucose), the animals were eviscerated and the spinal cord was exposed by ventral laminectomy. The spinal cord was dissected out to preserve the integrity of the ventral roots, pinned down in a perfusion chamber, and perfused with oxygenated aCSF (in mu: $128 \mathrm{NaCl}, 4.69 \mathrm{KCl}, 25 \mathrm{NaHCO}_{3}, 1.18$ $\mathrm{KH}_{2} \mathrm{PO}_{4}, 1.25 \mathrm{MgSO}_{4}, 2.5 \mathrm{CaCl}_{2}, 22 \mathrm{D}$-glucose) at room temperature. Embryos without reflex response were dissected first. The spinal cords of the litter mates were then dissected and put in a chamber filled with aCSF, continuously oxygenated, until recordings were started. Suction electrodes were attached to left and right lumbar (L)2 and L5 ventral roots and the spinal cord was equilibrated at least $30 \mathrm{~min}$ before application of neurotransmitter chemicals. A combination of NMDA $(0-10 \mu \mathrm{M})$, serotonin $(5-\mathrm{HT})(3-15 \mu \mathrm{M})$, and dopamine $(0-50 \mu \mathrm{M})$ were added to the perfusing aCSF to induce stable locomotor-like output. All chemicals were obtained from Sigma. The signals were amplified 10,000 times and bandpass filtered $10 \mathrm{~Hz}$ to $5 \mathrm{kHz}$ (model 1700; A-M Systems, Carlsborg, WA). The signals were A/D converted (Digidata 1322A; Molecular Devices) before being recorded on a PC (Axoscope 9.0.2.05) for later offline analysis. Data analysis of the recorded signals was performed as 


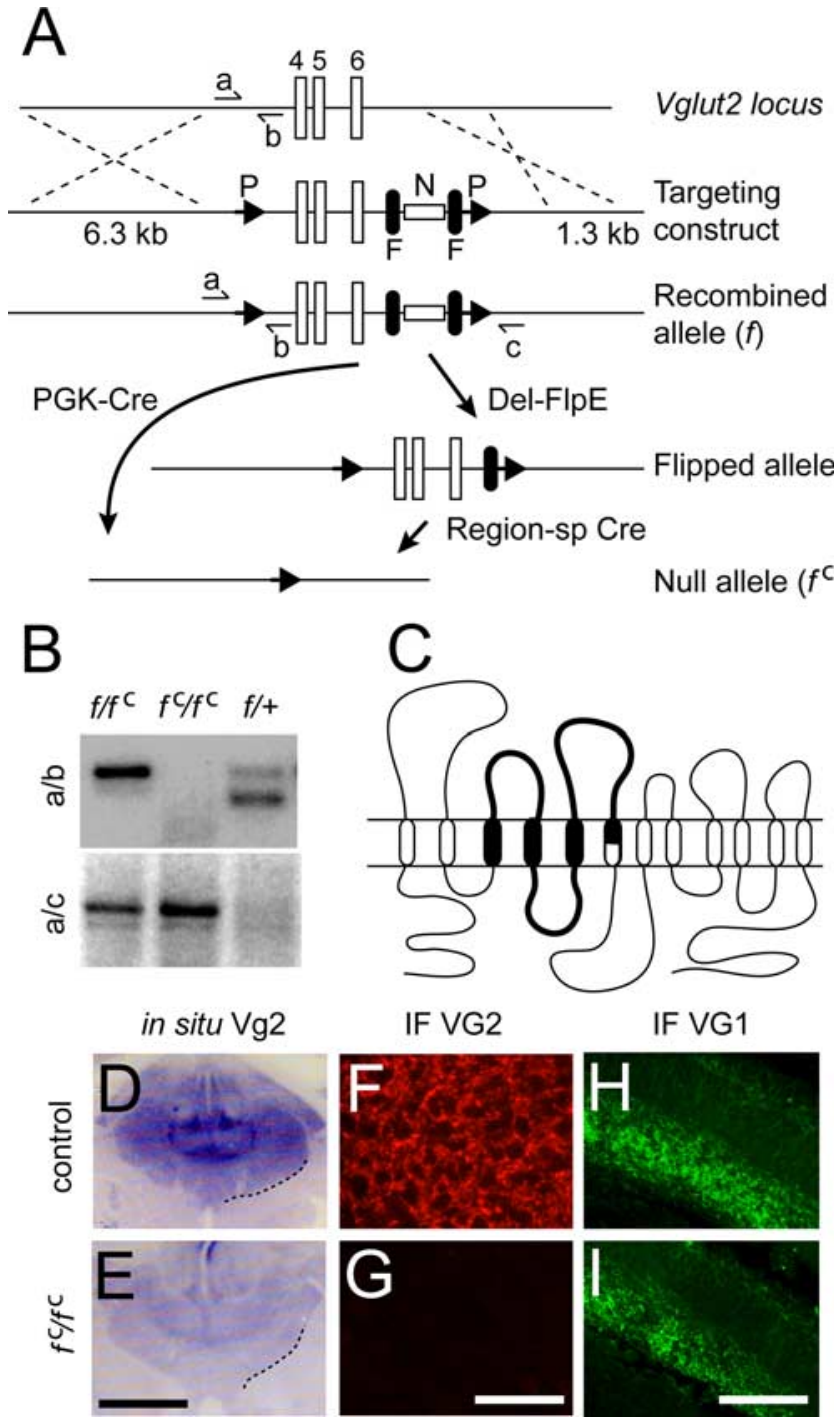

Figure 1. Gene targeting of the Vglut2 locus results in specific loss of VGLUT2 protein expression. $A$, The gene targeting strategy shows exons 4, 5, 6 in the Vglut2 locus flanked by a $5^{\prime}$ lox $P$ (P) site and a 3' Frt (F)-flanked Neo (N) cassette followed by a second loxP site in the targeting construct and the resulting recombined allele $(f) . A 6.3 \mathrm{~kb}^{\prime}$ arm and a $1.3 \mathrm{~kb} 3^{\prime}$ arm were used for homologous recombination sequence. The locations of $P C R$-oligos used for genotyping are labeled with a, b, and c; a, CTGTCCACCTTTGTATCCCA; b, GCAATCACATTTCACTGTTC; c, CACACCCACTCCACTTGAGG. General Cre-mediated recombination using PGK-Cre mice (PCre) (Lallemand et al., 1998) results in a null allele designated Vglut2 ${ }^{f \text { fPre }}\left(f f^{\subsetneq}\right)$. Deleter-FlpE (Del-FlpE)mediated recombination removes the Neo cassette, and region-specific (sp) Cre-mediated deletion results in a region-specific null allele. $B, P C R$ primer combination $a+b$ (top) results in a 150 bp band corresponding to the wt allele ( + ), a 184 bp band to the $f$ allele, and no band to the $f^{c}$ allele, whereas $a+c$ (bottom) results in a 327 bp band in the $f^{c}$ allele and no band in the $f$ and + alleles. The $f / f^{c}$ genotype thus results in 184 and 327 bp bands, the $f^{c} / f^{c}$ genotype in a 327 bp band, and the $\mathrm{f} /+$ genotype in 150 and 184 bp bands. C, Schematic drawing of the VGLUT2 protein structure including 12 transmembrane domains and interconnecting loops of which transmembrane domains 3, 4, 5, and part of 6, and loops 3, 4, and 5 (thick line) are deleted after (re-mediated recombination. $\mathbf{D}-\mathbf{I}$, In situ hybridization and immunofluorescence (IF) expression analysis in control and Vglut $2^{f / f \text { P }}$ (re brains shows strong Vglut2 $\mathrm{mRNA}(\boldsymbol{D})$ and protein $(\boldsymbol{F})$ in control thalamus and a weak mRNA expression but complete absence of protein, in the same region in the Vglute ${ }^{f f f ; P C r e}$ brain. VGLUT1 protein expression was normal in the hippocampus of control and Vglut2 ${ }^{f f f P(r e}$ embryos $(\boldsymbol{H}$, I). Scale bars: $\boldsymbol{E}, 1.3 \mathrm{~mm} ; \mathbf{G}, 160 \mu \mathrm{m} ; \mathbf{I}, 65 \mu \mathrm{m}$.

described previously (Kjaerulff and Kiehn, 1996); the onset of each burst was determined directly from recordings without rectifying the signals. The intrasegmental left/right alternations were analyzed in either L2 or L5 roots, and the intersegmental L2/L5 alternations were analyzed on either the right or left side in each animal. Only traces showing a stable
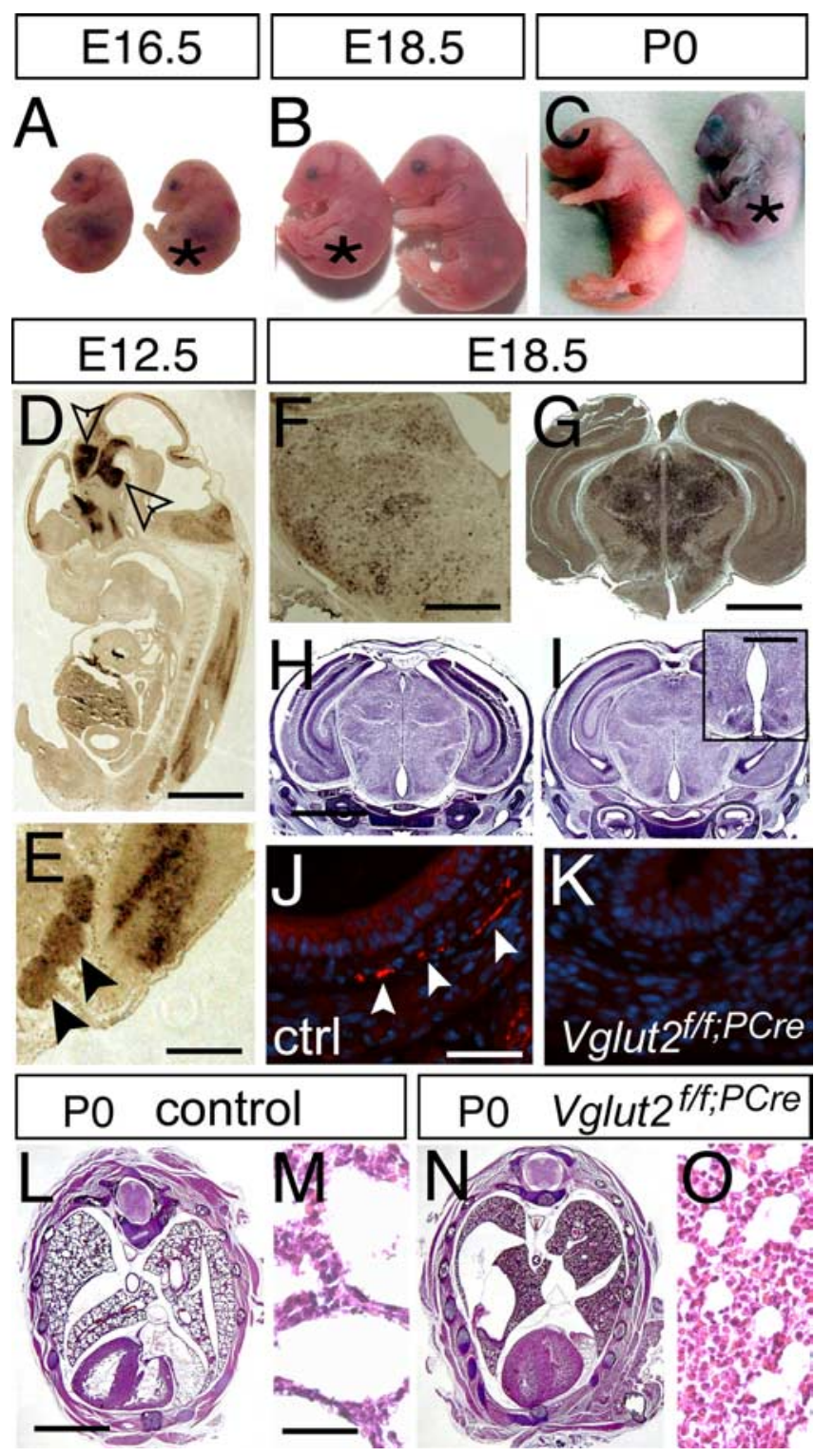

Figure 2. Vglut2 is expressed early in the embryo and is essential for normal development. $A-C$, Vglut2 ${ }^{f f f f P r e}$ embryos (*) appear arrested in development and can be distinguished from control littermates already at E16.5 by their hunched posture $(\boldsymbol{A})$. AtE18.5 (B), their smaller size (weights: control, $1.31 \pm 0.03 \mathrm{~g}, n=49 ;$ Vglut $^{f f f ;} ; \mathrm{PCre}, 1.20 \pm 0.03 \mathrm{~g}, n=20 ; p=$ 0.0269 ) is easily distinguished at PO. C, The pups display cyanosis and die directly after birth. $\boldsymbol{D}, \boldsymbol{E}, \mathrm{V}$ glut2 in situ hybridization of E12.5 embryos reveals strong mRNA expression in distinct brain regions (D), such as the ventral and dorsal diencephalon and ventral mesencephalon (arrows), brainstem, spinal cord, and dorsal root ganglia (close-up in $\boldsymbol{E}$, marked with arrows) and also along the telencephalic and fourth ventricles and the aqueduct. $\boldsymbol{F}, \boldsymbol{G}$, Vglut2 continues to be strongly expressed in the brainstem $(\boldsymbol{F})$ and the thalamus during late development (G). $\boldsymbol{H}, \boldsymbol{I}$, Hematoxylin/eosin staining of control $(\boldsymbol{H})$ and Vglut ${ }^{f f f ; P(r e}$ embryos $(\boldsymbol{I})$ coronal sections at E18.5 shows grossly normal brain histology of the null mutant compared with control, except a few animals ( $n=4 / 9$, E18.5 and $\mathrm{PO}$ ) that displayed enlarged appearance of ventricles (e.g., third ventricle) (inset in $I$ ). $\boldsymbol{J}, \boldsymbol{K}$, VGLUT2-positive nerve terminals (red) are readily detected by immunofluorescence (nuclear costaining with DAPI in blue) in control internal organs at E18.5, as shown here in transverse sections of the muscular wall of the esophagus $(J)$, whereas these nerve terminals are undetectable in the null mutants $(\boldsymbol{K})$. $\boldsymbol{L}-\boldsymbol{O}$, Hematoxylin/eosin staining of transverse sections of control and Vglut ${ }^{f f ;}$;Cre $P 0$ bodies shows grossly normal histology of the mutant compared with control except in the lungs, where the control display normal alveolar appearance (close-up in $\boldsymbol{M}$ ), whereas an immature, noninflated structure is manifest in the mutant (close-up in $\mathbf{0}$ ). Scale bars: $\boldsymbol{D}, 1 \mathrm{~mm} ; \boldsymbol{E}, 0.25 \mathrm{~mm} ; \boldsymbol{F}, 730 \mu \mathrm{m} ; \boldsymbol{G}$, $0.3 \mathrm{~mm} ; \boldsymbol{H}, 1.7 \mathrm{~mm}$; I, inset, $0.5 \mathrm{~mm} ; \boldsymbol{J}, 45 \mu \mathrm{m} ; \boldsymbol{L}, 2 \mathrm{~mm} ; \boldsymbol{M}, 40 \mu \mathrm{m}$. 
rhythmic activity were analyzed for coordination coupling. Vector points were derived from 15 random locomotor cycles. Each point represents the endpoint of a vector, the direction given by the mean phase value, and the length given by the focus of phase values around the mean. A phase value of 0.5 reflects alternating activity, and 0.0 reflects synchronous activity.

\section{Results}

Vglut $2^{\mathrm{f} / \mathrm{f} \text { PCre }}$ mutants die at birth

We generated a Vglut2 deficient allele by replacing part of the Vglut2 gene with a targeting construct by homologous recombination in ES cells (Fig. 1A). Successful targeting produced a modified allele with a loxP site preceding exons 4,5 , and 6 , and a neomycine selection cassette flanked by Frt sites, followed by a second loxP site. We confirmed the correct targeting event in the ES cells and in the animals by Southern blotting (data not shown) and a PCR strategy (Fig. $1 B$ ). Vglut $2^{f / f}$ mice carrying the entire construct were viable, fertile, and subsequently bred to PGK-Cre mice (Lallemand et al., 1998) to delete the targeted region including the neo cassette. The region flanked by the loxP sites contains three exons coding for a substantial part of the protein including three and a half transmembrane domains and two large extracellular loops (Fig. 1C). A transcript containing the $3^{\prime}$ end of the mRNA was detectable by in situ hybridization, albeit at very low levels compared with control tissue (Fig. 1D,E). We failed to detect VGLUT2 protein by immunohistochemistry (Fig. $1 C, F$ ), whereas we found normal levels of the closely related VGLUT1 protein in the brain (Fig. $1 H, I$ ). This suggests that removal of the targeted region severely affects transcription efficiency and that there is no detectable VGLUT2 protein product in null mutant mice.

None of the mice homozygous for the null allele $\left(\right.$ Vglut $\left.2^{f / f P C r e}\right)$ survived at birth $(n=20)$. Litters from embryonic stages E12.5 to E18.5 all showed a normal Mendelian ratio of genotypes, indicating that lethality occurred at birth. Observation of delivering females revealed that Vglut2 $2^{f / f P C r e}$ pups were born completely immobile with a beating heart that rapidly ceased as they became cyanotic (Fig. 2C). Of 20 null mutant pups dissected out at E18.5, none had a functional toe-pinch reflex, whereas 44 of 49 tested heterozygote or wt siblings responded with limb movements. Vglut 2 mRNA is expressed in developing dorsal root ganglia (Fig. $2 D, E$ ) containing cell bodies of sensory neurons, and dysfunction of these sensory neurons provides one explanation for the absence of a reflex response. Furthermore, Vglut $2^{f / f ; P C r e}$ embryos were hunched, significantly smaller (Fig. $2 A, B$ ), and weighed $1.20 \pm 0.03 \mathrm{~g}$, which was $8 \%$ less than littermate controls (control, $n=49 ; V_{g l u t}{ }^{f /}$ $f ;$ PCre mutants, $n=20 ; p=0.0269$ ). Because of the early expression of Vglut2 both in the nervous system (Fig. 2D-G),
Wildtype
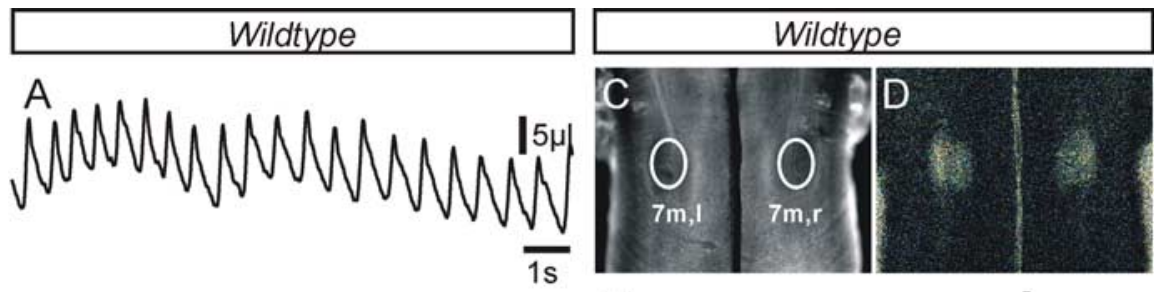

E

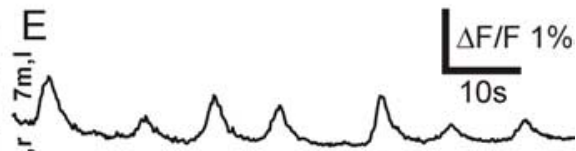

$|5 \mu|$

$1 \mathrm{~s}$

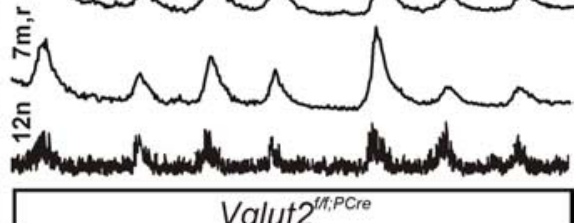

Wildtype
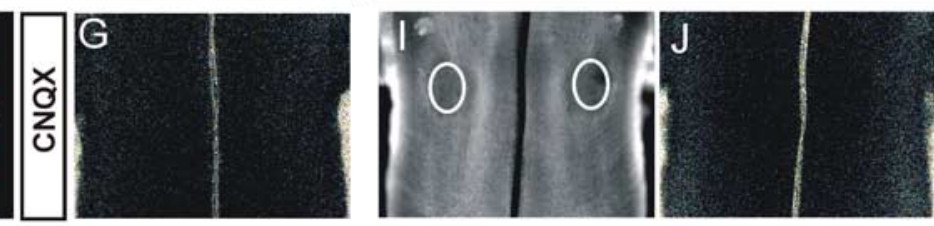

$\mathrm{H}$

$\Delta F / F \quad 1 \%$

$\mathrm{K}$

$\Delta \mathrm{F} / \mathrm{F} 1 \%$

$7 \mathrm{~m}, 1$

10s

m

$7 \mathrm{~m}, \mathrm{r}$

$12 n$

Figure 3. Vglut $2^{f / f ; P C r e}$ mutants do not breathe and fail to generate a central respiratory-like rhythm. $\boldsymbol{A}, \boldsymbol{B}$, Plethysmographic ratory cycles with alternating inspiratory (upward deflections) and expiratory (downward deflections) phases, whereas all Vglut ${ }^{f / f ; P C r e}$ mutants $(\boldsymbol{B})$ did not show any sign of ventilation. $\boldsymbol{C}, \boldsymbol{D}$, Photomicrographs of a whole E16.5 wt hindbrain preparation and right (r) facial motor nuclei (white outlines $7 \mathrm{~m}, \mathrm{I}$ and $7 \mathrm{~m}, \mathrm{r}$ in $\boldsymbol{C}$ ). $\boldsymbol{E}$, Corresponding fluorescence changes $(\Delta F / F)$ after loading whole hindbrain isolated preparation with Calcium Green-1AM are shown superposed to the hypoglossal nerve (12n) integrated electrical activity. $\boldsymbol{F}$, Photomicrograph of a whole-mount hindbrain preparation double immunostained for NK1R (red) and the torneuron marker Islet1,2 (green) demonstrates that the position of the right facial motor nucleus matches the location of the both rhythmic calcium changes over the facial motor nuclei $(\boldsymbol{G}, \boldsymbol{H})$ and accompanying electrical activity of the $12 \mathrm{n}(\boldsymbol{H}$, bottom trace). $\boldsymbol{I}$, The $V$ glut $2^{f / f ; P(r e}$ mutants showed normal hindbrain morphology $(\boldsymbol{I})$ but never displayed calcium transients over the facial motor nuclei $(\boldsymbol{J})$ nor electrical hypoglossal motor activity $(\boldsymbol{K})$.

and in peripheral organs (Fig. $2 J, K$ ), we speculated that the early dysfunction of glutamate signaling mediated by VGLUT2 could potentially lead to developmental defects. We therefore analyzed whether such defects were present in E18.5 embryos and P0 pups.

Comparing Vglut $2^{f f ; P C r e}$ E18.5 embryos with littermate controls, the gross morphology of the brain appeared normal (Fig. $2 \mathrm{H}, \mathrm{I})$. However, in four of nine E18.5 and P0 Vglut $2^{f f f P C r e}$ mice, the third ventricle appeared enlarged and reminded us more of an embryo at stage E16.5 (Fig. 2 I, inset). We then analyzed embryos at E12.5 (control, $n=2$; Vglut2 $2^{f / f P C r e}, n=2$ ), E15.5 (control, $n=$

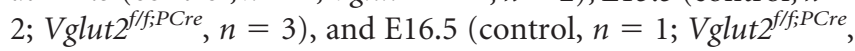
$n=1$ ), but we did not detect any defects with regard to brain morphology or proliferation (data not shown). In contrast, in Vglut $2^{f / f ; P C r e}$ neonates, lung alveoli were considerably reduced in size, indicating that the lungs had never been inflated (Fig. $2 \mathrm{~L}-\mathrm{O})$. 


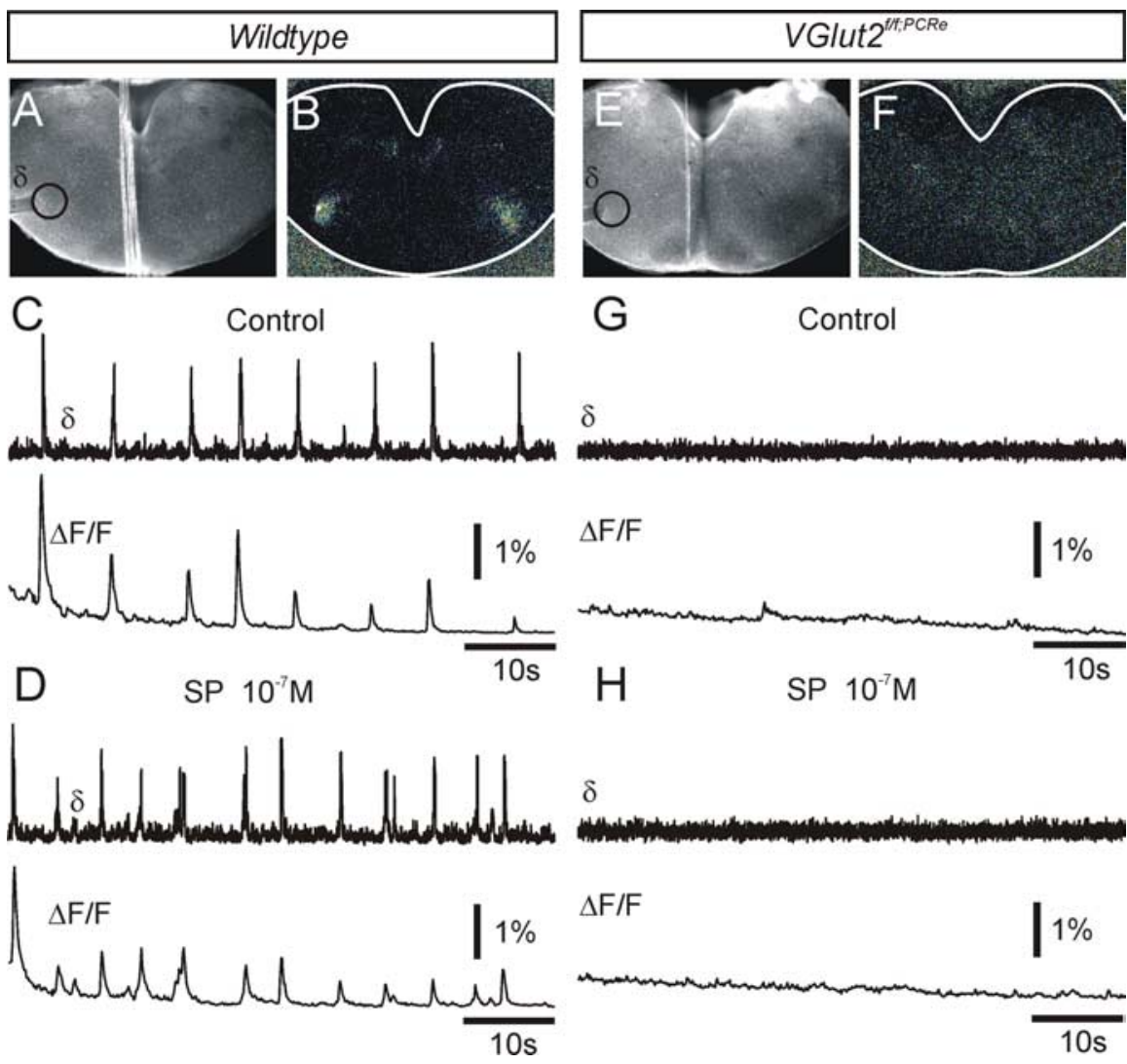

Figure 4. Vglut $2^{f / f ; P c r e}$ embryos lack a functional PBC rhythmogenic neural network. $\boldsymbol{A}, \boldsymbol{B}$, Direct and relative fluorescence photomicrographs of a transverse medulla slice from an E16.5 wt embry0. A suction electrode $(\delta)$ was used to record the PBC population electrical activity $(\delta)(\boldsymbol{C}, \boldsymbol{D}$, top trace). Loading of the calcium indicator Calcium Green-1AM was used to record the associated relative increase in fluorescence $(\triangle F / F)(\boldsymbol{C}, \boldsymbol{D}$, bottom trace) of the left PBC region (black circle). Note the correlation between bursts of electrical activity and calcium transients characterizing the $\mathrm{PBC}$ rhythmic activity in control $(\boldsymbol{C})$ and after bath application of the excitatory neuromodulator SP (D). $\boldsymbol{E}, \boldsymbol{F}$, In the Vglut $2^{f / f}$ Pcre mutant, no sign of electrical or optical organized activity could be noticed in control condition $(\boldsymbol{G})$ or induced by bath application of $\operatorname{SP}(\boldsymbol{H})$.

\section{Complete absence of rhythmic activity in the PBC of Vglut $2^{f / f ; P C r e}$ mutants}

The cyanosis, noninflated lung morphology, and immediate postnatal death prompted a functional investigation of ventilation and respiratory generating circuits in the brainstem of the embryo. In vivo measurement of the ventilation of wt $(n=3)$, heterozygous $(n=6)$, and Vglut $2^{\text {ff; PCre }}$ homozygous mutants $(n=4)$ were performed on fetuses surgically delivered at E18.5 (from two mice). Wild-type and heterozygous siblings (nine of nine) immediately initiated breathing and showed a stable breathing behavior $\sim 10 \mathrm{~min}$ after delivery at a frequency of $139 \pm 12$ breath $\cdot \min ^{-1}$ (Fig. $3 A$ ). In contrast, Vglut $2^{f / f P C r e}$ mutant littermates failed to show any respiratory behavior in a 3-5 min postdelivery period when they were placed in a plethysmographic chamber (Fig. 3B).

Breathing movements in rodent embryos arise before birth and respiratory-related rhythmic activity in the mouse is first detected at E15.5 in en bloc brainstem and slice preparations (Suzue and Shinoda, 1999; Kobayashi et al., 2001; Thoby-Brisson et al., 2005). Suspecting that altered lung morphology could have resulted from impaired central respiratory command, we first used E16.5 brainstem en bloc preparations to check the presence of rhythmic activity on cranial motor nerve outputs in wt $(n=2)$, heterozygous $(n=6)$, and Vglut $2^{f / f P C r e}$ mutants $(n=4)$. Electrophysiological recording from the hypoglossal nerve root $(12 n)$ while optically recording changes in fluorescence occurring over the facial motor nuclei $(7 \mathrm{~m})$ demonstrated bilateral rhythmic changes in fluorescence over the $7 \mathrm{~m}$ synchronized with rhythmic bursts of activity of the $12 \mathrm{n}$. Rhythmic activities emerging from wt and heterozygous mutant preparations were similar, with a combined average frequency for the rhythm of $9.5 \pm 1.3$ bursts $\cdot \mathrm{min}^{-1}$ (Fig. $3 C-E)$. Application of the AMPA/kainate receptor antagonist CNQX $(10 \mu \mathrm{M} ; n=4)$ suppressed both $12 \mathrm{n}$ electrical and $7 \mathrm{~m}$ optically detected activities (Fig. $3 F-H$ ). In control conditions, recordings performed on Vglut $2^{f / f ; P C r e}$ mutant preparations revealed the absence of both spontaneous electrical activity of the $12 \mathrm{n}$ and accompanying changes in fluorescence over the facial motor nuclei areas (Fig. 3I-K). Hence, the Vglut $2^{f \prime}$ f;PCre mutants showed a complete impairment of respiratory-related rhythmic motor output.

We next examined premotor rhythm generation at the level of the PBC on another set of embryos. We recorded the neuronal activity within the PBC from brainstem transverse slices. The spontaneous activity of the PBC cellular population was recorded from 11 slices from either wt or heterozygous embryos through calcium imaging and extracellular electrophysiological recordings at E16.5, $\sim 24 \mathrm{~h}$ after it becomes first active (Thoby-Brisson et al., 2005). In all cases, a spontaneous rhythmic activity could be recorded and visualized through associated changes in fluorescence in the $\mathrm{PBC}$ area of the slice (Fig. $4 A-C$ ) (Thoby-Brisson et al., 2005). Bath application of the $\mu$-opioid agonist DAMGO $(0.3 \mu \mathrm{M})$ first slowed and then reversibly fully suppressed the PBC rhythm (data not shown), whereas SP $(0.1 \mu \mathrm{M})$ increased the rhythm frequency from $8.0 \pm 1.4$ burst $\cdot \min ^{-1}(n=5)$ to $14.5 \pm 2.5$ burst $\cdot \min ^{-1}$ (Fig. $4 D$ ). Furthermore, blockade of AMPA/kainate receptors with bath application of CNQX $(10 \mu \mathrm{M})$ abolished the rhythm $(n=5)$ [see below and also Thoby-Brisson et al. (2005)]. In contrast, no activity could be recorded from corresponding seven of seven slices (E15.5, $n=2$; E16.5, $n=2$; E17.5, $n=1$; E18.5, $n=2$ ) from Vglut $2^{f / f ; P C r e}$ mice (Fig. $\left.4 E-G\right)$. Prolonged (15 min) applications of SP $(0.1 \mu \mathrm{M} ; n=3)$ (Fig. $4 H)$ or $\operatorname{NMDA}(5 \mu \mathrm{M} ; n=2)$ (data not shown) failed to induce rhythmic activity.

\section{The PBCs in Vglut2 mutants have contralateral projections} but no longer communicate over the midline

Commissural synaptic relationships across ventrolaterally located PBC areas in E16.5 transverse slices from wt and Vglut $2^{f / f P C r e}$ mutants were investigated by electrical and chemical stimulation. In wt slices, unilateral electrical stimulation of the PBC (Fig. $5 A-C)$ resulted in evoked bilateral bursts mixed with spontaneously occurring rhythmic bursts. The same stimulus in Vglut $2^{f / f ; P C r e}$ mutant slices instead evoked a calcium response restricted ispilaterally in the vicinity of the stimulation site (Fig. 5J-L). When the stimulating electrode was placed in a medial position to stimulate $\mathrm{PBC}$ axonal connections crossing the midline 
(Koshiya and Smith, 1999), it resulted in bilateral evoked calcium responses of the PBCs in wt slices (Fig. 5D-F). In Vglut2 $2^{f / f ; P C r e}$ mutant slices, midline stimulation could also elicit a calcium response in the expected location of the PBC (Fig. 5M-O). However, the amplitude of this response was reduced $\sim 10$-fold and resembled the response evoked in wt slices after blockade of AMPA/kainate receptors with CNQX (Fig. 5G-I). Finally, orthodromic recruitment of the contralateral PBC through commissural interneurons was assessed by chemical stimulation. Local pressure application of a glutamate agonist or GABA onto the PBC on one side is known to induce bilateral calcium variation in wt E15.5 PBC slices (ThobyBrisson et al., 2005). Here, pressure application of the glutamate agonist AMPA ( $1 \mathrm{mM} ; 50 \mathrm{~ms} ; 0.5$ bar) on the PBC on one side resulted in bilateral PBC calcium responses in wt slices $(n=3)$ (data not shown). However, the same AMPA application in $V_{\text {glut }} 2^{f / f ; P C r e}$ slices $(n=2)$ (Fig. $5 P-R$ ) elicited a calcium response limited to the injection site, demonstrating that local AMPA responsive cells were unable to synaptically propagate their excitation contralaterally. Hence, in the mutant, the small-amplitude PBC-evoked responses to electrical stimulation from the midline probably arose from antidromic activation of preserved commissural PBC neurons. These experiments indicate a conserved albeit nonfunctional PBC-like commissural connectivity in the Vglut $2^{f / f ; P C r e}$ mutant.

\section{The brainstem nuclei involved in respiration appear morphologically normal}

We next characterized the structural and cellular organization of several nuclei located in the brainstem that are known to be part of the central respiratory network. Embryo sections at E16.5 and E18.5 were analyzed by in situ hybridization and immunohistochemistry. At E18.5, the locations, distributions, and the size of cellular populations of upper airway motorneurons in the hypoglossal nucleus (XII), the vagal nucleus $(\mathrm{X})$, and nucleus ambiguous (NA) as well as phrenic motoneurons (MN) in the cervical spinal cord were similar in wt and Vglut2 $2^{f / f}$ PCre embryos as shown by VAChT mRNA expression (Fig. $6 C-H)$. In Figure $6, D$ and $G$, the area of the PBC is boxed to show its location; however, this is a VAChTnegative nucleus. Phox $2 \mathrm{~b}$ mRNA expression (Pattyn et al., 2000b) was used to localize the locus ceruleus (LC), the A1/C1 nucleus, and the nucleus of the solitary tract (NTS) in sections at
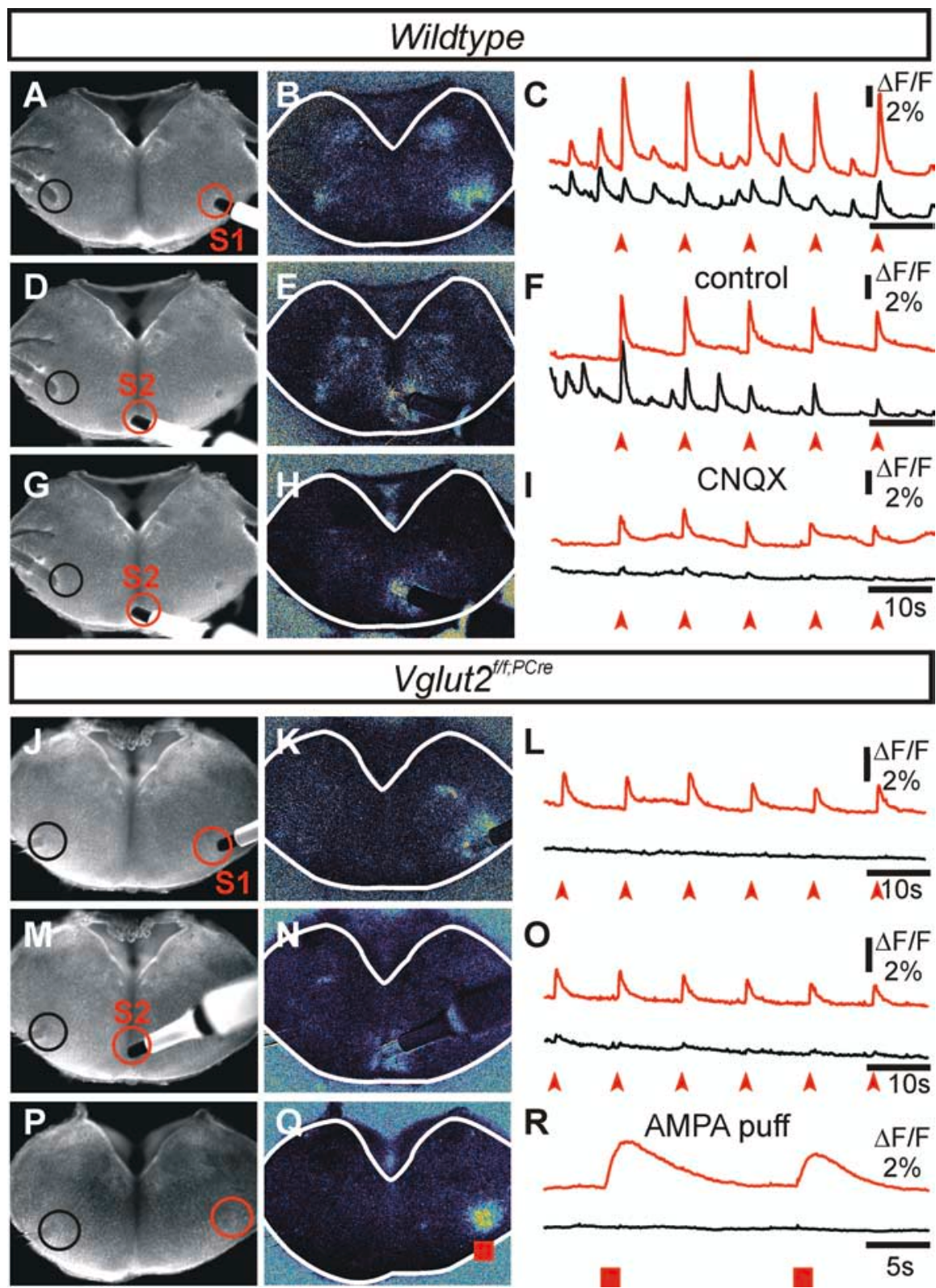

$\mathbf{R}$

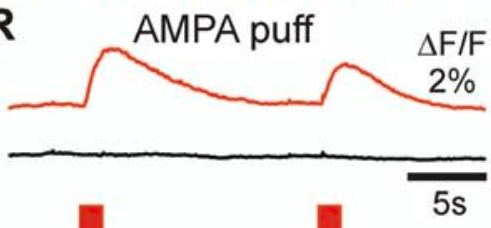

Figure 5. Excitatory commissural communication between $\mathrm{PBC}$ ventrolateral areas is impaired in E16.5 Vglut2 $2^{f / f}$,Pcre mutant transverse slices. Communication between bilaterally located PBCs through commissural projections was compared in wt $(\boldsymbol{A}-\boldsymbol{I})$ and Vglut ${ }^{f / f ; P c r e}$ mutants $(\boldsymbol{J}-\mathbf{0})$. $\boldsymbol{A}-\boldsymbol{C}$, Direct fluorescence image $(\boldsymbol{A})$ showing the position of the stimulation electrode (S1) over the right $\mathrm{PBC}$ and regions used to detect calcium changes over the stimulated $\mathrm{PBC}$ (red outline) and the contralateral PBC (black outline). $\boldsymbol{B}$, Evoked relative calcium change over the slice in response to $S 1$. $\boldsymbol{C}$, Fluorescence $(\Delta F / F)$ traces color matched to regions shown in $\boldsymbol{A}$. The top red trace in $\boldsymbol{C}$ corresponds to calcium transients (upward arrowheads) occurring in red outlined region of the $\mathrm{PBC}$ ipsilateral to the stimulus. Note in the wt the bilateral activation of dorsomedial regions. Synchronous ipsilateral and contralateral (black trace) PBC-evoked responses are intermixed with spontaneous rhythmic activity in wt slices $(\boldsymbol{D}-\boldsymbol{F})$. In contrast, evoked activity fails contralaterally in the Vglut2 $^{f / f ; P c r e}$ mutant $(\boldsymbol{J}-\boldsymbol{L})$, which are also spontaneously inactive. $\boldsymbol{D}-\boldsymbol{F}$, Stimulation over the midline commissure (S2) in wt slices evoked a local (red trace) and a bilateral response of the PBC (black trace; left PBC response) as well as activation of dorsomedial regions of the slice in the vicinity of hypoglossal motorneurons. In corresponding $V g / u t 2^{f / f ; P c r e}$ mutant slices $(\boldsymbol{M}-\mathbf{0})$, the $\mathrm{PBC}$-evoked response to $\mathrm{S2}(\boldsymbol{0}$, black trace) shows a considerably reduced amplitude reminiscent of that obtained in the wt context after application of $\operatorname{CNQX}(\boldsymbol{G}, \boldsymbol{H}) . \boldsymbol{P}-\boldsymbol{R}$, Pressure application of AMPA over the right PBC area in V glut $2^{f / f ; P c r e}$ mutant $(\boldsymbol{Q}, \boldsymbol{R}$, red squares) evoked a calcium response restricted to the immediate vicinity of the injection site ( $\boldsymbol{R}$, red trace), thus failing to orthodromically propagate to the contralateral PBC area ( $\boldsymbol{R}$, black trace).

E18.5 (Fig. 6 A shows control sections; Vglut $2^{\text {ff; PCre }}$ sections are not shown). Adjacent sections were then processed for immunoreactivity of VGLUT2 and nuclei-specific markers. VGLUT2positive nerve terminals are seen closely surrounding $\mathrm{TH}$-expressing 


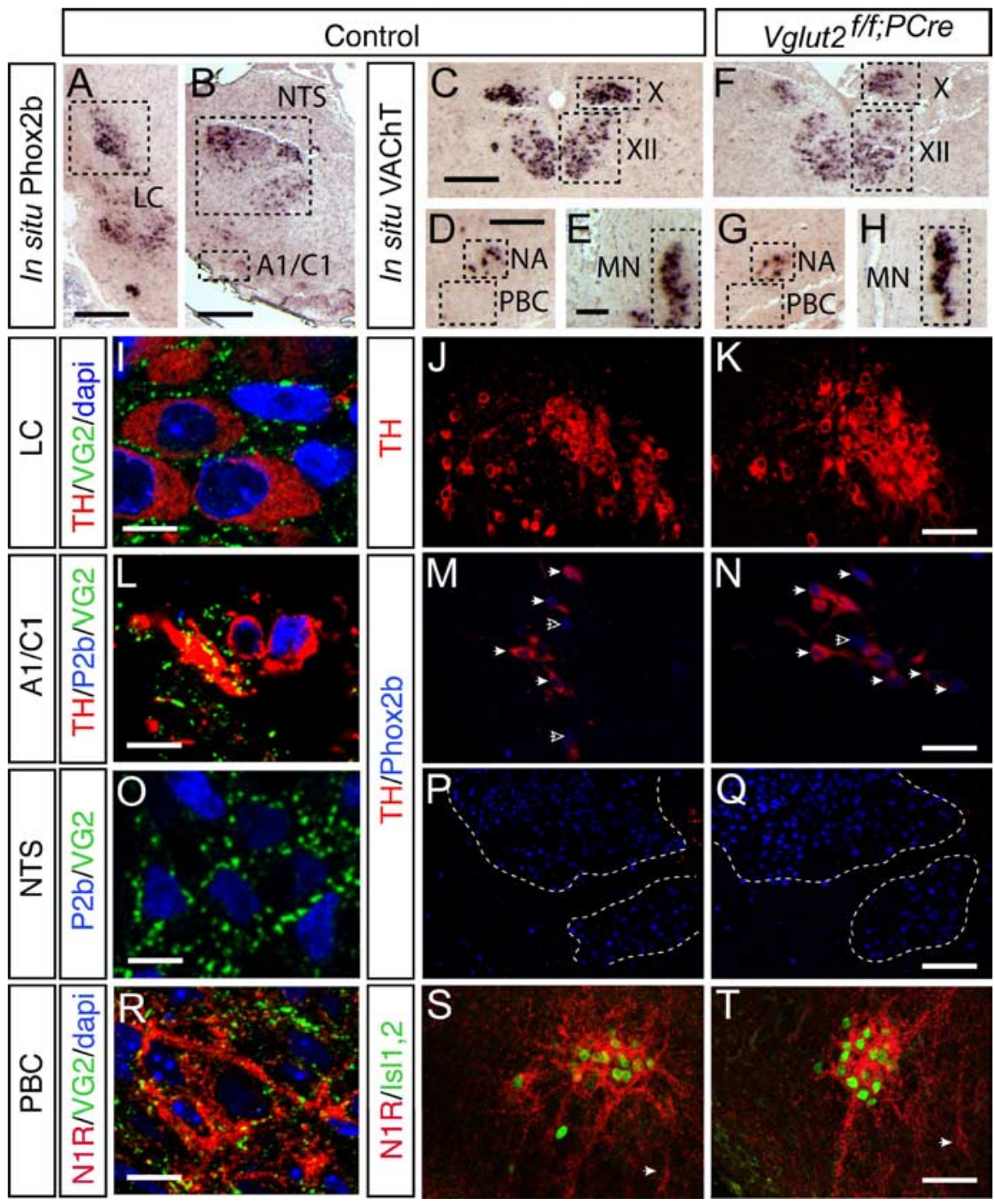

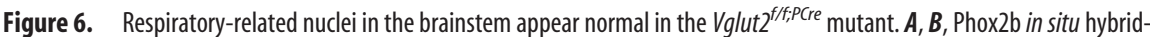
ization on coronal sections of E18.5 wt embryos shows the locations of several nuclei involved in regulation of respiratory function including the $L C(\boldsymbol{A})$, the NTS $(\boldsymbol{B})$, and the $A 1 / C 1$ noradrenergic/adrenergic nucleus (A1/C1) $(\boldsymbol{B}) . \boldsymbol{C}-\boldsymbol{H}$, VAChT in situ hybridization on adjacent section shows the location of other respiratory-related nuclei; the dorsal nucleus of the vagus nerve $(X)$, the hypoglossal nucleus (XII) (both on $\boldsymbol{C}$ ), the ambiguous nucleus (NA) (D), and the anterior spinal motor neurons (MN) (E). In the Vglut $^{f / f ; P(r e}$, these nuclei appear normal $(\boldsymbol{F}, \mathrm{X}$ and XII; $\boldsymbol{G}, \mathrm{NA} ; \boldsymbol{H}, \mathrm{MN})$. Note, in $\boldsymbol{D}$, the approximate area of the PBC is boxed to visualize its location; however, this is a VAChT-negative nucleus. $I-I$, Immunofluorescence analyses with specific markers of the respiratory nuclei at E18.5 shown in $\boldsymbol{A}$ and $\boldsymbol{B}$, in which the left panel shows the location of VGLUT2-positive terminals (green) in the $L C(I$, colabeling with TH in red and DAPI in blue), A1/C1 [ $\boldsymbol{L}$, TH in red and Phox $2 b(P 2 b)$ in blue], NTS $(0, P 2 b$ in blue), and also the PBC $[\boldsymbol{R}$, neurokinin-1-receptor (N1R) in red and DAPI in blue]. The middle and right panels show the entire nuclei at lower magnification; NTS with TH in red $(\boldsymbol{J}, \boldsymbol{K}), \mathrm{A} 1 \mathrm{C} 1$ with TH in red and Phox2b in blue $(\boldsymbol{M}, \boldsymbol{N})$, NTS with Phox2b in blue $(\boldsymbol{P}, \boldsymbol{Q})$, and PBC and NA visceral motor neurons with N1R in red and islet1,2 in green $(S, T)$ in the control $(J, M, P, S)$ and Vglut ${ }^{f / f ; P C r e}(K, N, Q, T)$ brains. No major structural differences between the two genotypes could be detected in these nuclei. In particular, note in $S$ and $\boldsymbol{T}$ the conserved organization of the PBC area including NK1R + /islet1,2-interneurons (white arrowheads) ventral and medial to the NA. Scale bars: $\boldsymbol{A}, 410 \mu \mathrm{m} ; \boldsymbol{B}, 320 \mu \mathrm{m} ; \boldsymbol{C}, 270 \mu \mathrm{m} ; \boldsymbol{D}, 230 \mu \mathrm{m} ; \boldsymbol{E}, 72 \mu \mathrm{m} ; \boldsymbol{I}, 13 \mu \mathrm{m} ; \boldsymbol{K}, 75 \mu \mathrm{m} ; \boldsymbol{L}, 9 \mu \mathrm{m} ; \boldsymbol{N}, 35 \mu \mathrm{m} ; \mathbf{0}, 21 \mu \mathrm{m}$; R, $13 \mu \mathrm{m} ; \mathbf{Q}, 150 \mu \mathrm{m} ; \mathbf{T}, 50 \mu \mathrm{m}$

noradrenergic neurons in the LC (Fig. 6I), Phox 2b/THexpressing neurons in the noradrenergic/adrenergic $\mathrm{A} 1 / \mathrm{C} 1$, and Phox2b-expressing neurons in the NTS (Fig. 6O). In sections covering the PBC area, VGLUT2-positive terminals were detected on NK1R-positive PBC neurons (Guyenet et al., 2002; Liu et al., 2003; Stornetta et al., 2003a,b) (Fig. 6R). We then examined how loss of Vglut2 expression affects these nuclei. The neurons of the LC had a normal distribution and number of cells in Vglut $2^{f /}$ f;PCre E18.5 embryos (Fig. 6J,K), which was true also for the
A1/C1 nucleus and the NTS (Fig. $6 M, N, P, Q)$. Medial in the NTS, the THexpressing noradrenergic/adrenergic A2/C2 nucleus could be detected in both control and Vglut $2^{f / f ; P C r e}$ brains (Fig. $6 P, Q)$ (data not shown). Finally, the organization of NK1R/islet1,2-immunopositive visceral motorneurons in the nucleus ambiguous and NK1R-positive $\mathrm{PBC}$ neurons appeared similar in control and Vglut $2^{f / f ; P C r e}$ embryos at both E16.5 (Fig. 6S,T) and E18.5 (data not shown). Together, these data indicate that components of the respiratory network in Vglut $^{f \prime}$ $f$; PCre embryos are present and have normal locations and size, suggesting little impact on brainstem structures and expression of genetic markers.

\section{Fast, excitatory synaptic events are} abolished in Vglut $2^{f / f ; P C r e}$ mutants We next analyzed how lack of VGLUT2 affected the activity of individual neurons of the PBC area. The ongoing synaptic activity present in neurons of the PBC area of wt and $V g l u t 2^{f / f ; P C r e}$ mutants was examined on transverse slices. Whole-cell voltage-clamp experiments, using a high chloride concentration (26 $\mathrm{mm}$ ) intrapipette solution, indicated that the spontaneous synaptic activity in wt preparation was composed of fast and slow decaying inward synaptic currents (Fig. 7A-D) (15 cells from two E18.5 slices). Slow but not fast synaptic currents were abolished in the presence of bicuculline and strychnine (Fig. 7D), indicating that they were likely mediated by $\mathrm{GABA}_{\mathrm{A}}$ and glycinergic receptors. In all cases, fast synaptic events resistant to bicuculline and strychnine (Fig. 7D) were abolished by additional application of CNQX (data not shown). Hence, the fast synaptic events were mediated by AMPA/kainate receptors. Interestingly, the spontaneous synaptic activity recorded in neurons of the PBC area in Vglut $2^{f / f ; P C r e}$ slices (12 cells from two slices) revealed the selective absence of fast synaptic events (Fig. $7 E-G$ ). Additional application of bicuculline and strychnine suppressed all remaining synaptic activity in $\mathrm{Vglut} 2^{f / f ; P C r e}$ mutant preparations (Fig. $7 H$ ). Hence, the absence of population synchronous rhythmic activity in the expected location of the PBC in Vglut $2^{f / f ; P C r e}$ mutants is associated to the lack of AMPA/kainate receptor-mediated synaptic processing.

Neurons with intrinsic bursting properties are preserved in the PBC area in Vglut $2^{f / f ; P C r e}$ mutants

Rhythm generation in the PBC may also rely on a small proportion (5-25\%) of cells capable of intrinsic bursting (Del Negro et 
al., 2002; Pena et al., 2004; Pagliardini et al., 2005; Thoby-Brisson et al., 2005). Such neurons remain active when glutamatergic synaptic transmission is blocked by CNQX (Smith et al., 1991; Koshiya and Smith, 1999; ThobyBrisson and Ramirez, 2001; Johnson et al., 2002; Thoby-Brisson et al., 2005). We recorded the spontaneous calcium changes occurring in individual neurons of the PBC area in $V g l u t 2^{f / f ; P C r e}$ mutant transverse slices (Fig. 8A,B). Continuous 1 min samplings of the activities from 46 neurons (from two E16.5 slices) indicated that the majority of neurons (34) presented spontaneous transient calcium changes and that the remainder of neurons were silent. The active neurons showed a large cell-to-cell variability in both the frequencies (range, 1-15 calcium events per minute) and amplitudes $(\Delta F / F, 1-5 \%)$ of calcium events. In contrast to what is observed in wt slices (Thoby-Brisson et al., 2005), we failed to detect occurrence of phased calcium events between different cells. However, among the active cellular population, three cells $(\sim 5 \%)$ displayed spontaneous periodic calcium changes (Fig. $8 C$ ). When substance $\mathrm{P}(0.1 \mu \mathrm{M})$ was bath applied, individual cells tended to show more calcium events, although this did not result in emergence of synchronous calcium events across the cellular population. Among cells with periodic bursting activity, substance $\mathrm{P}$ application resulted in an increased burst frequency in two of three cases (Fig. 8D, cell 8), whereas the remaining cells lost all calcium fluctuations. Interestingly, application of substance $\mathrm{P}$ also transformed the spontaneous activity in one cell from nonperiodic to periodic (Fig. 8, compare the activity of cell 3 in $C$ and $D$ ). Substance $\mathrm{P}$, probably acting on NK1 receptors present on neurons in the PBC area of $V g l u t 2^{\text {flf;PCre }}$ mutants (Fig. $6 S, T$ ), depolarized individual neurons in appropriate voltage domains in which the periodic busting pattern can either emerge, increase in frequency, or can no longer be maintained. In support of this, we detected voltage-dependent bursting properties in 1 of 12 neurons by whole-cell recordings (Fig. $8 E, F$ ). Collectively, these data strongly suggest that the Vglut2 ${ }^{f / f ; P C r e}$ mutant $\mathrm{PBC}$ area contain a small set of independently active neurons capable of intrinsic bursting.

\section{Synaptic vesicles are redistributed and malformed in asymmetric synapses}

We analyzed several brain regions by EM to determine the influence of VGLUT2 deficiency on synaptic morphology. In the pons, cortex, and hippocampus of control embryos, the asymmetric synapses contained round vesicles, whereas in the $V_{\text {glut }}{ }^{f / f ; P C r e}$ embryos, the vesicles had an elongated, drop-like, or irregular shape (data not shown). A closer analysis of the distribution and morphology of synaptic vesicles was per-

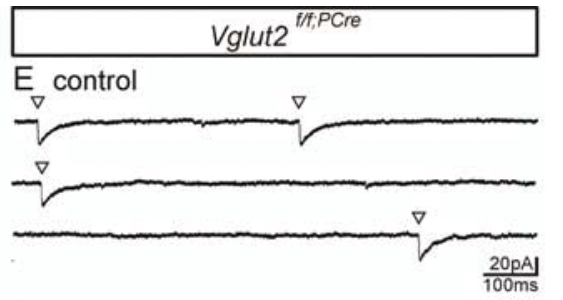

$\mathrm{F}$

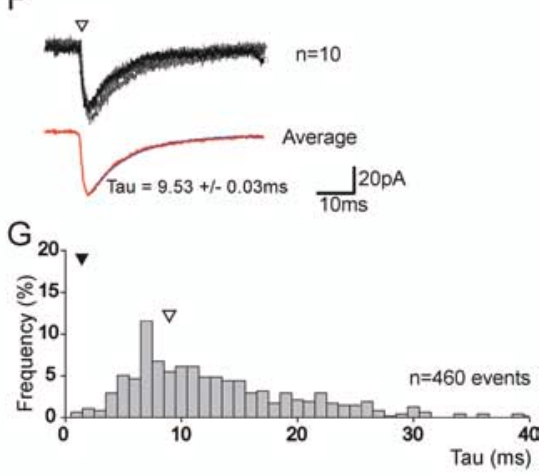

H Bic $10^{-6} \mathrm{M}+$ Stry $5.10^{-6} \mathrm{M}$

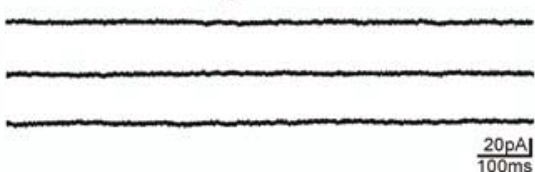

Figure 7. Loss of VGLUT2 results in the selective absence of fast excitatory synaptic events in neurons of the PBC area. $\boldsymbol{A}-\boldsymbol{D}$, Voltage-clamp whole-cell recordings of spontaneous inward synaptic currents in rhythmically active $\mathrm{PBC}$ neurons recorded in a wt E16.5 transverse slice and in nonrhythmic neurons of the PBC area recorded in a Vglut $2^{f / f ; P c r e}$ mutant slice $(\boldsymbol{E}-\boldsymbol{H})$. $\boldsymbol{A}$, Current traces showing in a representative wt neuron a characteristic mixture of fast (black triangles) and slow (empty triangles) inward synaptic frequency distribution of the decay time constant of synaptic events $(n=440)$ featuring a first peak corresponding to fast strychnine blocking chloride-mediated synaptic currents suppressed all slow synaptic events and left the fast events unaffected. glut2 ${ }^{r, P c r e}$ mutant neurons $(\boldsymbol{E}-\boldsymbol{H})$, almost all synaptic events were slow $(\boldsymbol{E}, \boldsymbol{F})$; fast synaptic events were found to be extremely scarce ( $<3 \%$; see the histogram in $\boldsymbol{G})$ resulting in a modal distribution of the decay time constants of all synaptic events $(n=460)$ in the slow event range (white triangle above histogram). Furthermore, blocking of $G_{A B A_{A}}$ and glycine receptors suppressed all slow events $(\boldsymbol{H})$. All current measurements were performed at a holding potential of $-70 \mathrm{mV}$.

formed at the level of the medulla in the hypoglossal motor region showing strong immunoreactivity for VGLUT2 (Fig. $9 A)$. Also, in this region, we found oddly shaped vesicles in asymmetric synapses from Vglut $2^{f / f ; P C r e}$ embryos (Fig. 9B-D) compared with control littermates (Fig. 9E). Quantification of the number of vesicles in each synapse revealed that symmetric synapses had a similar distribution of vesicles in wt and Vglut $2^{f / f ; P C r e}$ embryos (Fig. $\left.9 F, G, J\right)$. In contrast, asymmetric synapses from $V g l u t 2^{f / f}$;PCre embryos had a higher number of synapses containing only one vesicle than had littermate controls (Fig. 9H, $I, K)$. The average number of vesicles in symmetric synapses was similar between the genotypes with $5.5 \pm$ 0.6 in controls $(n=167$ synapses $)$ and $6.4 \pm 0.7(n=172)$ in $V_{\text {glut }}{ }^{f / f ; P C r e}$ embryos. In contrast, the average number of vesicles in asymmetric synapses in Vglut $2^{f / f ; P C r e}$ embryos $(3.7 \pm$ $0.4 ; n=108$ ) was significantly smaller ( $t$ test, $p=0.003$ ) compared with control embryos $(8.3 \pm 1.1 ; n=99)$. Because asymmetric synapses are generally excitatory (Kandel et al., 1991), our data demonstrate that, in excitatory terminals of Vglut $2^{\text {flf; } P C r e}$ embryos, synaptic vesicles are often malformed and are reduced in number with overrepresented terminals comprising only one vesicle. 

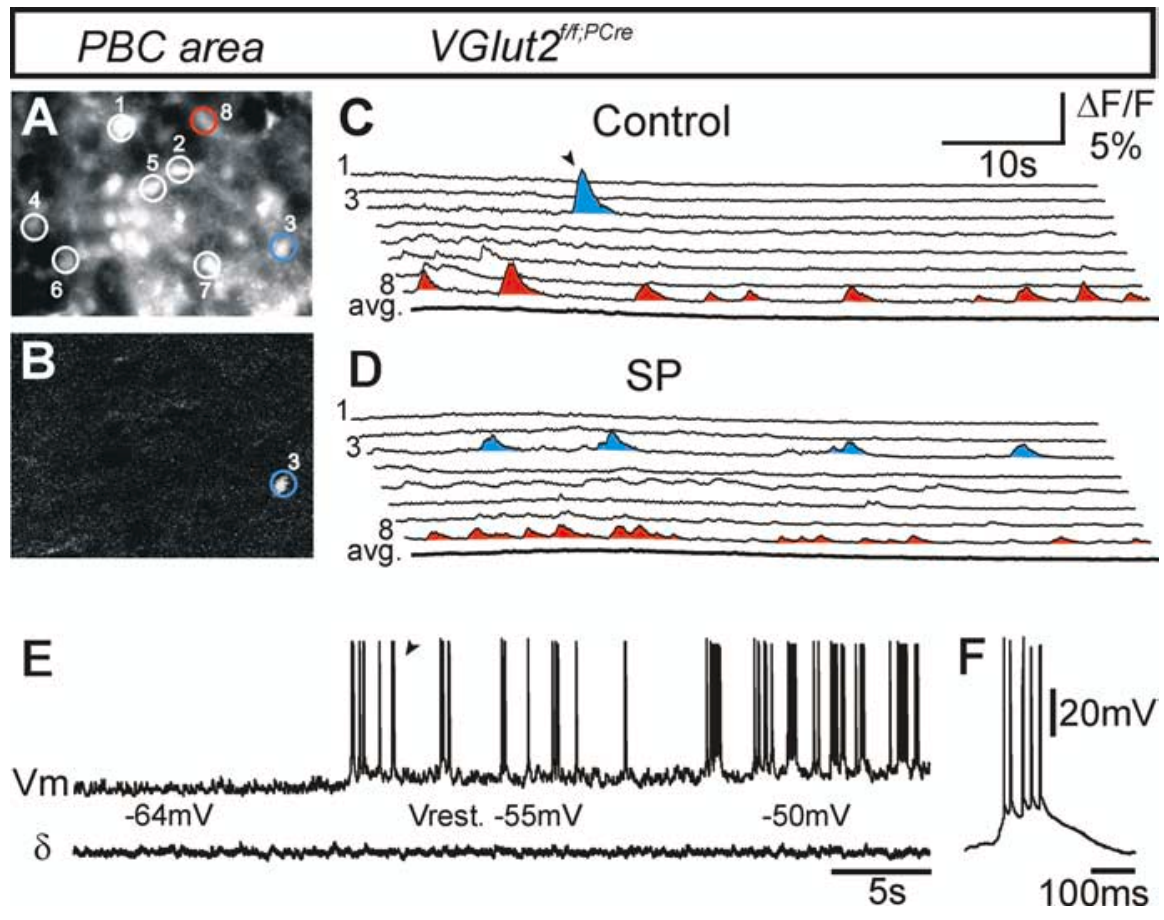

Figure 8. Neurons with intrinsic bursting properties are present in the PBC area of Vglut2 ${ }^{f / f ; P C r e}$ mutants. $\boldsymbol{A}-\boldsymbol{C}, \operatorname{Direct}(\boldsymbol{A})$ and relative $(\boldsymbol{B})$ fluorescence image at a cellular resolution ( $60 \times$ objective) of the PBC area in Vglut2 ${ }^{f / f P}$ ( $r e$ mutant transverse slices in control conditions. The changes in fluorescence were derived from the areas outlined around eight cells numbered $1-8(\boldsymbol{A})$ and are presented in $\boldsymbol{C}$. Calcium transients in cell 8 ( $\boldsymbol{A}$, red outline) are periodic, whereas cell 3 ( $\boldsymbol{A}$, blue outline) shows a single calcium event. The relative fluorescence image $(\boldsymbol{B})$ taken at the time indicated by an arrowhead in $\boldsymbol{C}$ illustrate that cell 3 is active when remaining cells are inactive. The average calcium signal ( $\boldsymbol{C}$, bottom thick trace) for the eight cells is flat, demonstrating the lack of synchronous calcium events. $D$, In the presence of SP $(0.1 \mu \mathrm{m})$, cells 3,5 , and 8 show increased number of bursts. Note that, in cell 3 , bursts are organized in a periodic manner under SP. Flat average signal ( $\boldsymbol{D}$, bottom thick average trace) indicates that absence of synchronous calcium events is maintained under SP. $\boldsymbol{E}$, Whole-cell current-clamp experiment showing the membrane potential $(V m)$ trajectory (top trace) of a neuron recorded in the PBC area in a Vglut $2^{f / f ; P C r e}$ mutant transverse slice and simultaneous population activity recording of the PBC area ( $\boldsymbol{D}$, bottom trace). At a hyperpolarized potential of $-64 \mathrm{mV}$, this neuron is inactive; at its resting membrane potential (Vrest., $-55 \mathrm{mV}$ ), it generates bursts of action potential (one such burst indicated by the arrowhead is shown with a faster time base in $\boldsymbol{F}$ ); and when further depolarized to $-50 \mathrm{mV}$, the bursts show increased duration and are generated at a higher frequency.

\section{Vglut2 deficiency spares the function of the locomotor CPG in vitro}

To evaluate the influence of Vglut2 deficiency in other CPG neurocircuits, we investigated functionality of the locomotor CPG for which excitatory neurons have been shown to be necessary components (Buchanan and Grillner, 1987; Grillner, 1997, 2003). Vglut2 is expressed already at stage E12.5 in the spinal cord (Fig. $10 \mathrm{~A}$ ). After birth, Vglut2 but not Vglut1, is abundantly expressed (Fig. $10 B, C$ ) in the ventral aspect of the spinal cord, which is known to be critical for locomotor rhythm generation (Kjaerulff and Kiehn, 1996). We therefore expected to detect major deficiencies in in vitro measurements of fictive locomotion. To induce fictive locomotion in dissected spinal cords from E18.5 fetuses, we added a combination of NMDA, serotonin, and dopamine (see also Materials and Methods). Surprisingly, the Vglut $2^{f / f ; P C r e}$ spinal cords showed in all seven preparations tested, a pattern of rhythmic left-right alternation as well as coordination of the lumbar level 2 and 5 activity with a periodicity indistinguishable from that recorded from control $(n=11)$ preparations (Fig. 10D-G). This is in stark contrast to the situation found in the respiratory $\mathrm{CPG}$, suggesting a dispensable role for VGLUT2 in the locomotor CPG.

\section{Discussion}

Here, we present the first functional study of VGLUT2 by conditional deletion in mice and demonstrate that VGLUT2 signaling is an essential component of the developing respiratory rhythm generator. VGLUT2-deficient mice fail to initiate synchronized rhythmic activity in the $\mathrm{PBC}$ and do not breathe at birth. Vglut $2^{f / f ; P c r e}$ mutants have fewer and malformed synaptic vesicles at asymmetric but not symmetric synapses in the hindbrain. This results in a selective impairment of AMPA/kainate receptor-mediated synaptic currents in neurons of the $\mathrm{PBC}$, which in turn prevents synchronized $\mathrm{PBC}$ population activity. We here suggest that VGLUT2 is necessary for PBC cells to function as a network with synchronized and rhythmic activity.

\section{Vglut $2^{\text {f/f;Pcre }}$ mutants fail to generate a} respiratory rhythm

The central rhythmic activity of the PBC beginning on E15.5 in the mouse and E16.5 in the rat is the first sign of respiratory-related activity in developing rodents (Pagliardini et al., 2003; ThobyBrisson et al., 2005) and is initiated shortly before the start of respiratory-like movements (Ezure, 1990). Spontaneous PBC area rhythmic activities in the Vglut2 $2^{f / f}$ Pcre mutant mouse was not observed at E15.5. Later on, at E16.5, central rhythm generation was missing at a stage when respiratory movements would normally be present. Fetal development of the lung is strongly influenced by mechanical forces arising from fluid inflation and fetal breathing movements (Alcorn et al., 1977; Tschumperlin and Drazen, 2006). The defective lungs found in Vglut $2^{f / f \text { Pcre }}$ mutants are consistent with absence of breathing movements. Therefore, the absence of ventilation in Vglut $2^{f / f ; P c r e}$ mutants observed in E18.5 fetuses in vivo and the cyanotic appearance of born mutants probably results from a deficient respiratory motor drive that has been dysfunctional throughout prenatal development. It would be interesting to investigate whether $V$ glut $2^{\text {ff; Pcre }}$ mutant fetuses also have other impaired primordial movements such as head flexions, hiccup, and startle movements that are set before onset of fetal breathing movements (de Vries et al., 1982; Suzue and Shinoda, 1999). Along the same line, it is presently unknown whether other brainstem networks such as those involved in regulation of swallowing, cardiovascular function, or sleep may also be functionally impaired in Vglut $2^{f / f \text { Pcre }}$ mutants. We conclude that VGLUT2-mediated signaling is crucial for the functional onset of the PBC and ventilation at birth.

The VGLUT2 deficiency does not alter the anatomy of central respiratory areas

Vglut $2^{f / f ; P c r e}$ mutants were here shown to develop in the absence of gross anatomical defects of the brainstem hosting central respiratory areas. The location and anatomical layout of the NTS, 
A1/C1, A2/C2, LC, dorsal motor nuclei of the vagus nerve, hypoglossal motor nuclei as well as the phrenic motorneuronal column in the cervical spinal cord appeared normal at E18.5 and P0. Phox $2 \mathrm{~b}$ and/or $\mathrm{TH}$ expression were unaltered in identified neuronal groups, suggesting that normal morphogenetic development occurs within the hindbrain of Vglut2 $2^{f / f \text { Pcre }} \mathrm{mu}$ tants. In Vglut $2^{f / f ; P C r e}$ mutants, the PBC area adjacent to normally developed A1/C1 nuclei hosted candidate PBC neurons characterized by NK1R expression ventrally located with respect to normally located Islet1,2/NK1R-positive NA visceral motorneurons (Gray et al., 1999). Furthermore, PBC commissural fibers as well as GABAergic/glycinergic inhibitory synapses are present in Vglut2 null mutants. Together, these results demonstrate that the anatomical integrity of the hindbrain and of the PBC in particular is preserved in Vglut $2^{f / f}$ :Pcre mutants.

Breathing defects that result from abnormal development of brainstem respiratory circuits have previously been described in genetically altered mice. In several mutants such as Mash1 (Dauger et al., 2004), Phox2a (Morin et al., 1997; Viemari et al., 2004), Phox2b (Pattyn et al., 2000a), Rnx (Shirasawa et al., 2000), Hoxa1 (del Toro et al., 2001), Krox20 (Jacquin et al., 1996), Ret (Viemari et al., 2005), and MafB (Blanchi et al., 2003), life-threatening apneas or irregularities of the respiratory rhythm have been demonstrated, but so far, none has shown a complete extinction of respiratory activity. These mutants preserve the capacity to generate inspiratory bursts even if their occurrence may be considerably reduced in frequency (Blanchi et al., 2003). Hence, mechanisms underlying the production of synchronized inspiratory bursts appear particularly robust and allow respiratory movements despite abnormal development of respiratory circuits. Interestingly, the Vglut2 $2^{f / f: P C r e}$ mutant is the only genetic model to date featuring both spared anatomical integrity and complete absence of synchronized activities in the PBC, throughout the prenatal period from E15.5 when these activities normally first appear, to P0 when they begin to control the breathing behavior. Intriguingly, our data point to VGLUT2-mediated activity having little influence on PBC circuit formation; however, this issue will need additional examination.

\section{Impaired vesicular transport of glutamate prevents emergence of synchronized neural activities in the PBC}

We have here found that the proportion of neurons in the PBC area showing voltage-dependent bursting pacemaker properties is comparable $(\sim 10 \%)$ between $V g l u t 2^{\text {f/f;PCre }}$ mutants and

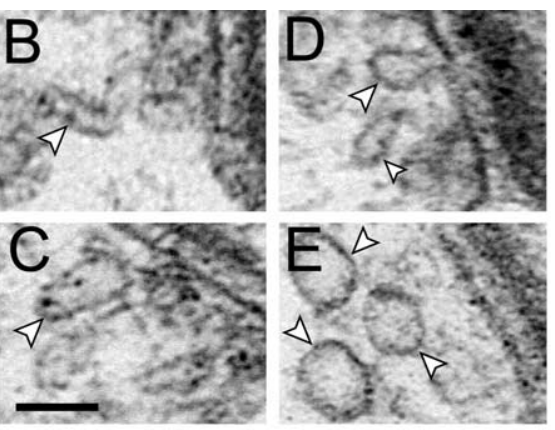

$\mathrm{K}$

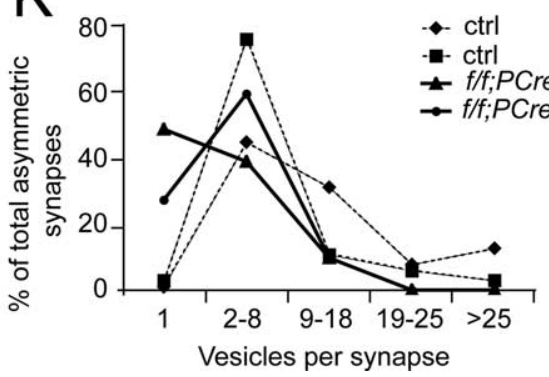

Vesicles per synapse
Asymmetrical synapses

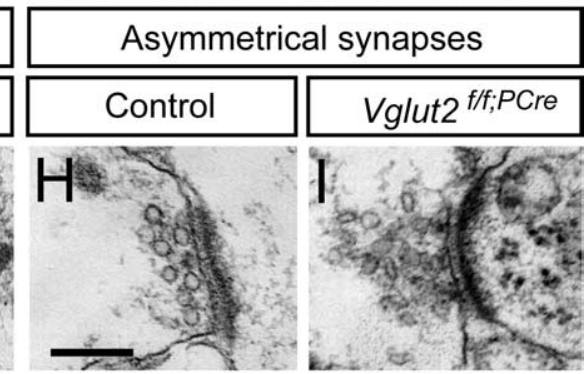

Figure 9. Loss of VGLUT2 results in altered morphology and reduced number of synaptic vesicles in asymmetric synapses. $\boldsymbol{A}_{\text {, }}$ VGLUT2 immunofluoresence (white) of the E18.5 brainstem showing the area selected for EM quantification (square). $\boldsymbol{B}-\boldsymbol{E}$, here by thin $(\boldsymbol{B})$ and thick $(\boldsymbol{C})$ elongated vesicles and a couple of drop-shaped and pointed vesicles $(\boldsymbol{D})$, whereas the control vesicles ow a regular, circular shape $(\boldsymbol{E})$. The white arrows indicate vesicle borders. $\boldsymbol{F}-\boldsymbol{I}$, Low magnification of synaptic structures not differ between control $(\boldsymbol{F})$ and $V g / u t 2^{f / f ; P(r e}(\boldsymbol{G})$, whereas asymmetric synapses, with thickened postsynaptic membrane in profiles do not differ significantly between controls and mutants; both have similar number of synapses in each Vglut $^{f / f} ;$; Pre brain, whereas no control synapses belong to this subgroup. Instead, control synapses contain a larger number of vesicles ( $8 \%$ have $19-25$ vesicles and up to $13 \%$ have $>25$ vesicles), whereas the corresponding number in the mutant for both these subgroups is zero. Scale bars: $\boldsymbol{A}, 155 \mu \mathrm{m} ; \boldsymbol{C}, 50 \mathrm{~nm} ; \boldsymbol{H}, 175 \mathrm{~nm}$.

CNQX-treated wt preparations (Thoby-Brisson et al., 2005). It is therefore likely that VGLUT2-mediated neurotransmission is dispensable for activation of the intrinsic membrane currents underlying intrinsic bursting of individual cells. Other synaptic inputs, including immature depolarizing chloride currents, exist in the Vglut $2^{f / f ; P C r e}$ mutants to activate bursting. Also, burstgenerating conductances are redundant. At least two have been identified, a persistent $\mathrm{Na}^{+}$current $\left(I_{\mathrm{NaP}}\right)$ (Smith et al., 1991; Del Negro et al., 2002; Johnson et al., 2002), and a $\mathrm{Ca}^{2+}$-activated nonspecific and voltage-insensitive cation current $\left(I_{\text {CAN }}\right)$ (Pena et al., 2004; Del Negro et al., 2005). Others probably exist because blockade of both $I_{\mathrm{NaP}}$ and $I_{\mathrm{CAN}}$ does not irremediably abolish the PBC ability to generate bursting activity (Del Negro et al., 2005). Active pacemaker neurons are unable to transmit and synchronize activation in the absence of VGLUT2. Therefore, because the 

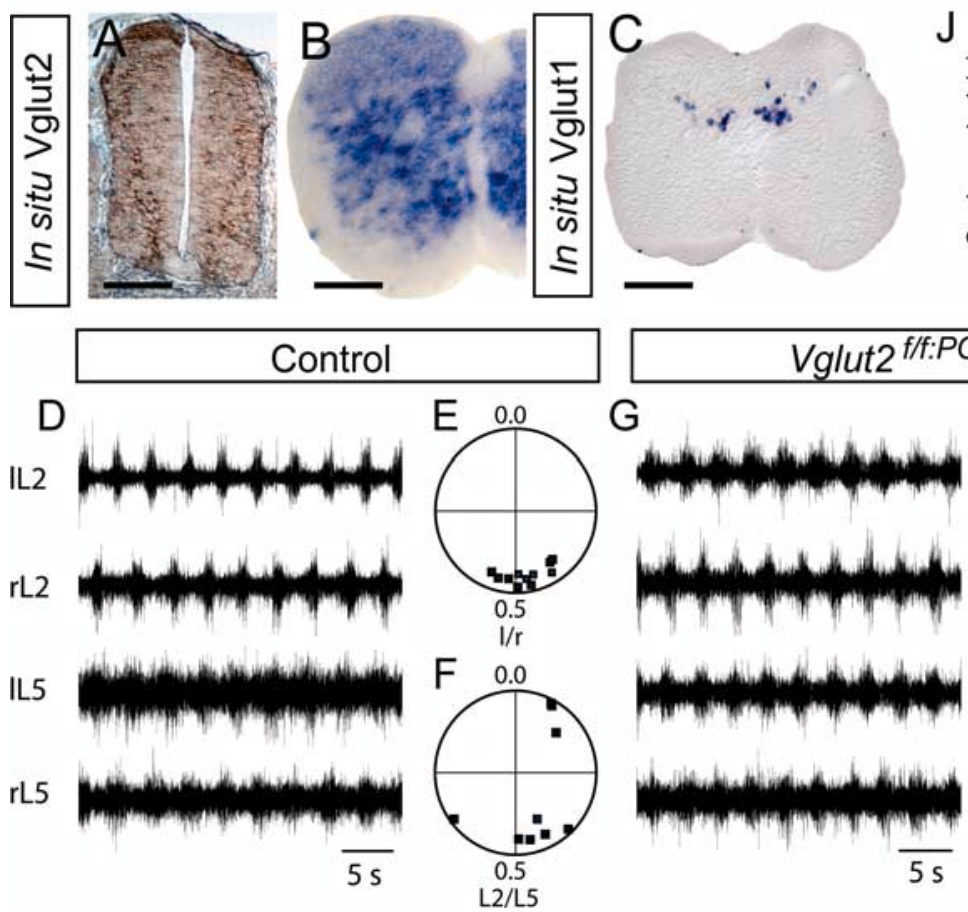

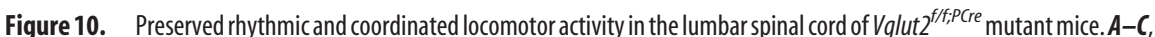
Vglut in situ hybridization on transverse wt sections of spinal cord shows expression at E12.5 $(\boldsymbol{A})$ and $\mathrm{PO}(\boldsymbol{B})$ of Vglut2 mRNA widely distributed, whereas Vglut1 mRNA is discretely expressed in the P11 dorsal spinal cord (C). D, G, Recorded activity in the lumbar ventral roots, at level 2 and 5, after application of NMDA and serotonin to the isolated spinal cord of E18.5 mice. The control (D) as well as the Vglut2 ${ }^{f / f}$ PCre mutant spinal cords $(\boldsymbol{G})$ show a normal alternating rhythmic locomotor activity. $\boldsymbol{E}, \boldsymbol{F}, \boldsymbol{H}, \boldsymbol{I}$, Circular phase diagrams of intrasegmental left/right $(\boldsymbol{E}, \boldsymbol{H})$ and intersegmental flexion/extension $(\boldsymbol{F}, \boldsymbol{I})$ coordination. A phase value of 0.5 reflects alternating activity, and 0.0 reflects synchronous activity. I, Left; r, right; L, lumbar segment. $\boldsymbol{J}$, The average period cycle time of control $(n=11)$ and Vglut $2^{f / f ; P C r e}(n=7)$ mice was not statistically different ( $\left.p=0.0680\right)$; the average was calculated from the mean period of 15 random locomotor cycles from each mouse. Error bars indicate SEM.

bursting process persists in neurons of the PBC area of VGLUT2 mutants despite the lack of breathing rhythm, our view on respiratory rhythm generation extends the recently proposed "group pacemaker hypothesis" (Feldman and Del Negro, 2006), which posits that inspirations result from recurrent excitations that preexist and activate membrane pacemaker properties. We propose the "synchronized group pacemaker hypothesis," in which the process to generate inspirations is a VGLUT2-sensitive glutamatergic synchronization of PBC bursts that may be produced by the various (and somewhat VGLUT2-independent) synaptic/intrinsic interactions within the group pacemaker.

Our hypothesis is built on the assumption that most $\mathrm{PBC}$ pacemaker neurons are glutamatergic, which still requires additional experimental support. It also remains poorly understood why in vivo, pharmacological blockade of AMPA/kainate receptors does not entirely eliminate breathing in neonatal mice (Borday et al., 1998). A simple explanation would be that pharmacology in vivo is unable to entirely disrupt glutamatergic transmission, whereas the present genetic inactivation does. The disruption of genes encoding glutamate NMDA receptor subunits (Forrest et al., 1994; Li et al., 1994; Sakimura et al., 1995; Ebralidze et al., 1996; Kadotani et al., 1996; Kutsuwada et al., 1996; Funk et al., 1997; Poon et al., 2000; Miyamoto et al., 2002), non-NMDA receptors (Jia et al., 1996, 2001; Pekhletski et al., 1996; Huettner, 2001; Gerlai et al., 2002; Morishima et al., 2005), glutamate-synthesizing enzyme (Masson et al., 2006), or of glutamate fate-determining selector genes (Cheng et al., 2004) failed to result in a complete collapse of
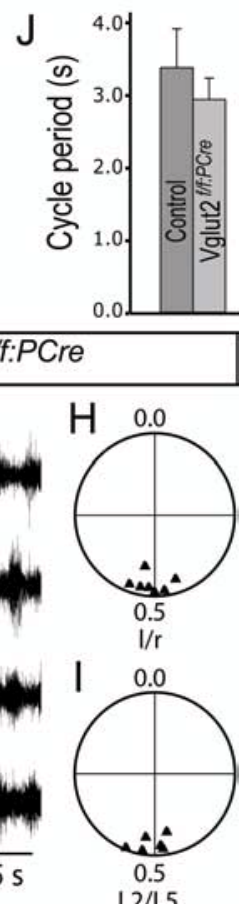

the respiratory activity. Hence, genetically impacting the glutamate neuron itself provides a powerful tool to interfere with the activity of neural circuits. Because the genetically targeted allele of Vglut2 used here can be conditionally deleted, future genetic dissection of excitatory components in many neural circuits is now possible.

Many neuronal populations express Vglut2 mRNA in the spinal locomotor CPG area (Kullander et al., 2003; Kiehn, 2006). These include populations of interneurons with ipsilateral or contralateral projections onto motorneurons as well as Hb9/Vglut2 double-positive ipsilaterally projecting interneurons hypothesized to be elements of the locomotor CPG (Butt and Kiehn, 2003; Butt et al., 2005; Wilson et al., 2005). Therefore, preservation of the rhythm generation, left/right alternation, and extensor/flexor coordination in VGLUT2-deficient mice is an unexpected finding. Additional experiments are required to investigate possible compensatory mechanisms including regulatory expression of other VGLUTs (Miyazaki et al., 2003). However, such compensations do not take place in the brainstem respiratory CPG, emphasizing the necessity of VGLUT2-mediated signaling in the respiratory $\mathrm{CPG}$.

In conclusion, we have shown that, when the functional maturation of glutamatergic synchronization in the PBC is missing during development, the resulting anomaly cannot be compensated by later plasticity. In contrast to spinal cord locomotor rhythm generation, the PBC activity and synchronization is dependent on VGLUT2-mediated signaling. Therefore, the present study identifies VGLUT2-mediated signaling as an obligatory component of the developing respiratory rhythm generator.

\section{References}

Alcorn D, Adamson TM, Lambert TF, Maloney JE, Ritchie BC, Robinson PM (1977) Morphological effects of chronic tracheal ligation and drainage in the fetal lamb lung. J Anat 123:649-660.

Bartlett Jr D, Tenney SM (1970) Control of breathing in experimental anemia. Respir Physiol 10:384-395.

Bellocchio EE, Reimer RJ, Fremeau Jr RT, Edwards RH (2000) Uptake of glutamate into synaptic vesicles by an inorganic phosphate transporter. Science 289:957-960.

Blanchi B, Kelly LM, Viemari JC, Lafon I, Burnet H, Bevengut M, Tillmanns S, Daniel L, Graf T, Hilaire G, Sieweke MH (2003) MafB deficiency causes defective respiratory rhythmogenesis and fatal central apnea at birth. Nat Neurosci 6:1091-1100.

Borday V, Foutz AS, Nordholm L, Denavit-Saubie M (1998) Respiratory effects of glutamate receptor antagonists in neonate and adult mammals. Eur J Pharmacol 348:235-246.

Buchanan JT, Grillner S (1987) Newly identified "glutamate interneurons" and their role in locomotion in the lamprey spinal cord. Science 236:312-314.

Butt SJ, Kiehn O (2003) Functional identification of interneurons responsible for left-right coordination of hindlimbs in mammals. Neuron 38:953-963.

Butt SJ, Lundfald L, Kiehn O (2005) EphA4 defines a class of excitatory 
locomotor-related interneurons. Proc Natl Acad Sci USA 102:14098-14103.

Cazalets JR, Gardette M, Hilaire G (2000) Locomotor network maturation is transiently delayed in the MAOA-deficient mouse. J Neurophysiol 83:2468-2470.

Chatonnet F, del Toro ED, Voiculescu O, Charnay P, Champagnat J (2002) Different respiratory control systems are affected in homozygous and heterozygous kreisler mutant mice. Eur J Neurosci 15:684-692.

Cheng L, Arata A, Mizuguchi R, Qian Y, Karunaratne A, Gray PA, Arata S, Shirasawa S, Bouchard M, Luo P, Chen CL, Busslinger M, Goulding M, Onimaru H, Ma Q (2004) Tlx3 and Tlx1 are post-mitotic selector genes determining glutamatergic over GABAergic cell fates. Nat Neurosci 7:510-517.

Dauger S, Durand E, Cohen G, Lagercrantz H, Changeux JP, Gaultier C, Gallego J (2004) Control of breathing in newborn mice lacking the beta-2 nAChR subunit. Acta Physiol Scand 182:205-212.

Del Negro CA, Koshiya N, Butera Jr RJ, Smith JC (2002) Persistent sodium current, membrane properties and bursting behavior of pre-Botzinger complex inspiratory neurons in vitro. J Neurophysiol 88:2242-2250.

Del Negro CA, Morgado-Valle C, Hayes JA, Mackay DD, Pace RW, Crowder EA, Feldman JL (2005) Sodium and calcium current-mediated pacemaker neurons and respiratory rhythm generation. J Neurosci 25:446-453.

del Toro ED, Borday V, Davenne M, Neun R, Rijli FM, Champagnat J (2001) Generation of a novel functional neuronal circuit in Hoxal mutant mice. J Neurosci 21:5637-5642.

de Vries JI, Visser GH, Prechtl HF (1982) The emergence of fetal behaviour. I. Qualitative aspects. Early Hum Dev 7:301-322.

Ebralidze AK, Rossi DJ, Tonegawa S, Slater NT (1996) Modification of NMDA receptor channels and synaptic transmission by targeted disruption of the NR2C gene. J Neurosci 16:5014-5025.

Ezure K (1990) Synaptic connections between medullary respiratory neurons and considerations on the genesis of respiratory rhythm. Prog Neurobiol 35:429-450.

Feldman JL, Del Negro CA (2006) Looking for inspiration: new perspectives on respiratory rhythm. Nat Rev Neurosci 7:232-242.

Forrest D, Yuzaki M, Soares HD, Ng L, Luk DC, Sheng M, Stewart CL, Morgan JI, Connor JA, Curran T (1994) Targeted disruption of NMDA receptor 1 gene abolishes NMDA response and results in neonatal death. Neuron 13:325-338.

Fremeau Jr RT, Troyer MD, Pahner I, Nygaard GO, Tran CH, Reimer RJ, Bellocchio EE, Fortin D, Storm-Mathisen J, Edwards RH (2001) The expression of vesicular glutamate transporters defines two classes of excitatory synapse. Neuron 31:247-260.

Fremeau Jr RT, Kam K, Qureshi T, Johnson J, Copenhagen DR, StormMathisen J, Chaudhry FA, Nicoll RA, Edwards RH (2004) Vesicular glutamate transporters 1 and 2 target to functionally distinct synaptic release sites. Science 304:1815-1819.

Fujiyama F, Furuta T, Kaneko T (2001) Immunocytochemical localization of candidates for vesicular glutamate transporters in the rat cerebral cortex. J Comp Neurol 435:379-387.

Funk GD, Smith JC, Feldman JL (1993) Generation and transmission of respiratory oscillations in medullary slices: role of excitatory amino acids. J Neurophysiol 70:1497-1515.

Funk GD, Johnson SM, Smith JC, Dong XW, Lai J, Feldman JL (1997) Functional respiratory rhythm generating networks in neonatal mice lacking NMDAR1 gene. J Neurophysiol 78:1414-1420.

Gerlai R, Adams B, Fitch T, Chaney S, Baez M (2002) Performance deficits of mGluR8 knockout mice in learning tasks: the effects of null mutation and the background genotype. Neuropharmacology 43:235-249.

Gray PA, Rekling JC, Bocchiaro CM, Feldman JL (1999) Modulation of respiratory frequency by peptidergic input to rhythmogenic neurons in the preBotzinger complex. Science 286:1566-1568.

Grillner S (1997) Ion channels and locomotion. Science 278:1087-1088.

Grillner S (2003) The motor infrastructure: from ion channels to neuronal networks. Nat Rev Neurosci 4:573-586.

Guyenet PG, Sevigny CP, Weston MC, Stornetta RL (2002) Neurokinin-1 receptor-expressing cells of the ventral respiratory group are functionally heterogeneous and predominantly glutamatergic. J Neurosci 22:3806-3816.

Herzog E, Bellenchi GC, Gras C, Bernard V, Ravassard P, Bedet C, Gasnier B, Giros B, El Mestikawy S (2001) The existence of a second vesicular glu- tamate transporter specifies subpopulations of glutamatergic neurons. J Neurosci 21:RC181(1-6).

Hioki H, Fujiyama F, Taki K, Tomioka R, Furuta T, Tamamaki N, Kaneko T (2003) Differential distribution of vesicular glutamate transporters in the rat cerebellar cortex. Neuroscience 117:1-6.

Huettner JE (2001) Kainate receptors: knocking out plasticity. Trends Neurosci 24:365-366.

Jacquin TD, Borday V, Schneider-Maunoury S, Topilko P, Ghilini G, Kato F, Charnay P, Champagnat J (1996) Reorganization of pontine rhythmogenic neuronal networks in Krox-20 knockout mice. Neuron 17:747-758.

Jia Z, Agopyan N, Miu P, Xiong Z, Henderson J, Gerlai R, Taverna FA, Velumian A, MacDonald J, Carlen P, Abramow-Newerly W, Roder J (1996) Enhanced LTP in mice deficient in the AMPA receptor GluR2. Neuron 17:945-956.

Jia Z, Lu YM, Agopyan N, Roder J (2001) Gene targeting reveals a role for the glutamate receptors mGluR5 and GluR2 in learning and memory. Physiol Behav 73:793-802.

Jiang Z, Carlin KP, Brownstone RM (1999) An in vitro functionally mature mouse spinal cord preparation for the study of spinal motor networks. Brain Res 816:493-499.

Johnson SM, Wilkerson JE, Wenninger MR, Henderson DR, Mitchell GS (2002) Role of synaptic inhibition in turtle respiratory rhythm generation. J Physiol (Lond) 544:253-265.

Kadotani H, Hirano T, Masugi M, Nakamura K, Nakao K, Katsuki M, Nakanishi S (1996) Motor discoordination results from combined gene disruption of the NMDA receptor NR2A and NR2C subunits, but not from single disruption of the NR2A or NR2C subunit. J Neurosci 16:7859-7867.

Kandel ER, Schwartz JH, Jessell TM (1991) Principles of neural science, Ed 3. East Norwalk, CT: Appleton and Lange.

Kiehn O (2006) Locomotor circuits in the mammalian spinal cord. Annu Rev Neurosci 29:279-306.

Kjaerulff O, Kiehn O (1996) Distribution of networks generating and coordinating locomotor activity in the neonatal rat spinal cord in vitro: a lesion study. J Neurosci 16:5777-5794.

Kobayashi K, Lemke RP, Greer JJ (2001) Ultrasound measurements of fetal breathing movements in the rat. J Appl Physiol 91:316-320.

Koshiya N, Smith JC (1999) Neuronal pacemaker for breathing visualized in vitro. Nature 400:360-363.

Kullander K, Butt SJ, Lebret JM, Lundfald L, Restrepo CE, Rydstrom A, Klein R, Kiehn O (2003) Role of EphA4 and EphrinB3 in local neuronal circuits that control walking. Science 299:1889-1892.

Kutsuwada T, Sakimura K, Manabe T, Takayama C, Katakura N, Kushiya E, Natsume R, Watanabe M, Inoue Y, Yagi T, Aizawa S, Arakawa M, Takahashi T, Nakamura Y, Mori H, Mishina M (1996) Impairment of suckling response, trigeminal neuronal pattern formation, and hippocampal LTD in NMDA receptor epsilon 2 subunit mutant mice. Neuron 16:333-344.

Lallemand Y, Luria V, Haffner-Krausz R, Lonai P (1998) Maternally expressed PGK-Cre transgene as a tool for early and uniform activation of the Cre site-specific recombinase. Transgenic Res 7:105-112.

Li Y, Erzurumlu RS, Chen C, Jhaveri S, Tonegawa S (1994) Whisker-related neuronal patterns fail to develop in the trigeminal brainstem nuclei of NMDAR1 knockout mice. Cell 76:427-437.

Liu YY, Wong-Riley MT, Liu JP, Jia Y, Liu HL, Jiao XY, Ju G (2002) GABAergic and glycinergic synapses onto neurokinin-1 receptorimmunoreactive neurons in the pre-Botzinger complex of rats: light and electron microscopic studies. Eur J Neurosci 16:1058-1066.

Liu YY, Wong-Riley MT, Liu JP, Jia Y, Liu HL, Fujiyama F, Ju G (2003) Relationship between two types of vesicular glutamate transporters and neurokinin-1 receptor-immunoreactive neurons in the pre-Botzinger complex of rats: light and electron microscopic studies. Eur J Neurosci $17: 41-48$.

Masson J, Darmon M, Conjard A, Chuhma N, Ropert N, Thoby-Brisson M, Foutz AS, Parrot S, Miller GM, Jorisch R, Polan J, Hamon M, Hen R, Rayport S (2006) Mice lacking brain/kidney phosphate-activated glutaminase have impaired glutamatergic synaptic transmission, altered breathing, disorganized goal-directed behavior and die shortly after birth. J Neurosci 26:4660-4671.

Miyamoto Y, Yamada K, Noda Y, Mori H, Mishina M, Nabeshima T (2002) Lower sensitivity to stress and altered monoaminergic neuronal function 
in mice lacking the NMDA receptor epsilon 4 subunit. J Neurosci 22:2335-2342.

Miyazaki T, Fukaya M, Shimizu H, Watanabe M (2003) Subtype switching of vesicular glutamate transporters at parallel fibre-Purkinje cell synapses in developing mouse cerebellum. Eur J Neurosci 17:2563-2572.

Mori S, Matsuyama K, Mori F, Nakajima K (2001) Supraspinal sites that induce locomotion in the vertebrate central nervous system. Adv Neurol $87: 25-40$

Morin X, Cremer H, Hirsch MR, Kapur RP, Goridis C, Brunet JF (1997) Defects in sensory and autonomic ganglia and absence of locus coeruleus in mice deficient for the homeobox gene Phox2a. Neuron 18:411-423.

Morishima Y, Miyakawa T, Furuyashiki T, Tanaka Y, Mizuma H, Nakanishi S (2005) Enhanced cocaine responsiveness and impaired motor coordination in metabotropic glutamate receptor subtype 2 knockout mice. Proc Natl Acad Sci USA 102:4170-4175.

Nishimaru H, Takizawa H, Kudo N (2000) 5-Hydroxytryptamine-induced locomotor rhythm in the neonatal mouse spinal cord in vitro. Neurosci Lett 280:187-190.

Paarmann I, Frermann D, Keller BU, Villmann C, Breitinger HG, Hollmann M (2005) Kinetics and subunit composition of NMDA receptors in respiratory-related neurons. J Neurochem 93:812-824.

Pagliardini S, Ren J, Greer JJ (2003) Ontogeny of the pre-Botzinger complex in perinatal rats. J Neurosci 23:9575-9584.

Pagliardini S, Adachi T, Ren J, Funk GD, Greer JJ (2005) Fluorescent tagging of rhythmically active respiratory neurons within the pre-Botzinger complex of rat medullary slice preparations. J Neurosci 25:2591-2596.

Pattyn A, Goridis C, Brunet JF (2000a) Specification of the central noradrenergic phenotype by the homeobox gene Phox2b. Mol Cell Neurosci $15: 235-243$.

Pattyn A, Hirsch M, Goridis C, Brunet JF (2000b) Control of hindbrain motor neuron differentiation by the homeobox gene Phox 2b. Development 127:1349-1358

Pekhletski R, Gerlai R, Overstreet LS, Huang XP, Agopyan N, Slater NT, Abramow-Newerly W, Roder JC, Hampson DR (1996) Impaired cerebellar synaptic plasticity and motor performance in mice lacking the mGluR4 subtype of metabotropic glutamate receptor. J Neurosci 16:6364-6373.

Pena F, Parkis MA, Tryba AK, Ramirez JM (2004) Differential contribution of pacemaker properties to the generation of respiratory rhythms during normoxia and hypoxia. Neuron 43:105-117.

Poon CS, Zhou Z, Champagnat J (2000) NMDA receptor activity in utero averts respiratory depression and anomalous long-term depression in newborn mice. J Neurosci 20:RC73(1-6).

Rekling JC, Feldman JL (1998) PreBotzinger complex and pacemaker neurons: hypothesized site and kernel for respiratory rhythm generation. Annu Rev Physiol 60:385-405.

Robinson D, Ellenberger H (1997) Distribution of N-methyl-D-aspartate and non- $N$-methyl-D-aspartate glutamate receptor subunits on respiratory motor and premotor neurons in the rat. J Comp Neurol 389:94-116.

Rodriguez CI, Buchholz F, Galloway J, Sequerra R, Kasper J, Ayala R, Stewart AF, Dymecki SM (2000) High-efficiency deleter mice show that FLPe is an alternative to Cre-loxP. Nat Genet 25:139-140.

Sakimura K, Kutsuwada T, Ito I, Manabe T, Takayama C, Kushiya E, Yagi T, Aizawa S, Inoue Y, Sugiyama H, et al. (1995) Reduced hippocampal LTP and spatial learning in mice lacking NMDA receptor epsilon 1 subunit. Nature 373:151-155.
Schuske K, Jorgensen EM (2004) Neuroscience. Vesicular glutamate transporter-shooting blanks. Science 304:1750-1752.

Shirasawa S, Arata A, Onimaru H, Roth KA, Brown GA, Horning S, Arata S, Okumura K, Sasazuki T, Korsmeyer SJ (2000) Rnx deficiency results in congenital central hypoventilation. Nat Genet 24:287-290.

Smith JC, Ellenberger HH, Ballanyi K, Richter DW, Feldman JL (1991) PreBotzinger complex: a brainstem region that may generate respiratory rhythm in mammals. Science 254:726-729.

Stornetta RL, Sevigny CP, Guyenet PG (2003a) Inspiratory augmenting bulbospinal neurons express both glutamatergic and enkephalinergic phenotypes. J Comp Neurol 455:113-124.

Stornetta RL, Rosin DL, Wang H, Sevigny CP, Weston MC, Guyenet PG (2003b) A group of glutamatergic interneurons expressing high levels of both neurokinin-1 receptors and somatostatin identifies the region of the pre-Botzinger complex. J Comp Neurol 455:499-512.

Suzue T, Shinoda Y (1999) Highly reproducible spatiotemporal patterns of mammalian embryonic movements at the developmental stage of the earliest spontaneous motility. Eur J Neurosci 11:2697-2710.

Takamori S, Rhee JS, Rosenmund C, Jahn R (2000) Identification of a vesicular glutamate transporter that defines a glutamatergic phenotype in neurons. Nature 407:189-194.

Takamori S, Rhee JS, Rosenmund C, Jahn R (2001) Identification of differentiation-associated brain-specific phosphate transporter as a second vesicular glutamate transporter (VGLUT2). J Neurosci 21:RC182(1-6).

Thoby-Brisson M, Ramirez JM (2001) Identification of two types of inspiratory pacemaker neurons in the isolated respiratory neural network of mice. J Neurophysiol 86:104-112.

Thoby-Brisson M, Trinh JB, Champagnat J, Fortin G (2005) Emergence of the pre-Botzinger respiratory rhythm generator in the mouse embryo. J Neurosci 25:4307-4318.

Tschumperlin DJ, Drazen JM (2006) Chronic effects of mechanical force on airways. Annu Rev Physiol 68:563-583.

Viemari JC, Bevengut M, Burnet H, Coulon P, Pequignot JM, Tiveron MC, Hilaire G (2004) Phox2a gene, A6 neurons, and noradrenaline are essential for development of normal respiratory rhythm in mice. J Neurosci 24:928-937.

Viemari JC, Maussion G, Bevengut M, Burnet H, Pequignot JM, Nepote V, Pachnis V, Simonneau M, Hilaire G (2005) Ret deficiency in mice impairs the development of A5 and A6 neurons and the functional maturation of the respiratory rhythm. Eur J Neurosci 22:2403-2412.

Whelan PJ (2003) Developmental aspects of spinal locomotor function: insights from using the in vitro mouse spinal cord preparation. J Physiol (Lond) 553:695-706.

Wilson JM, Hartley R, Maxwell DJ, Todd AJ, Lieberam I, Kaltschmidt JA, Yoshida Y, Jessell TM, Brownstone RM (2005) Conditional rhythmicity of ventral spinal interneurons defined by expression of the $\mathrm{Hb} 9$ homeodomain protein. J Neurosci 25:5710-5719.

Wojcik SM, Rhee JS, Herzog E, Sigler A, Jahn R, Takamori S, Brose N, Rosenmund C (2004) An essential role for vesicular glutamate transporter 1 (VGLUT1) in postnatal development and control of quantal size. Proc Natl Acad Sci USA 101:7158-7163.

Zhang Y, Muyrers JP, Testa G, Stewart AF (2000) DNA cloning by homologous recombination in Escherichia coli. Nat Biotechnol 18:1314-1317. 